Andrews University

Digital Commons @ Andrews University

2008

\title{
The Relationship Between Collective-Efficacy and Student Achievement in Vocational/Technical High Schools
}

Rosemary Tralli

Andrews University

Follow this and additional works at: https://digitalcommons.andrews.edu/dissertations

Part of the Secondary Education Commons

\section{Recommended Citation}

Tralli, Rosemary, "The Relationship Between Collective-Efficacy and Student Achievement in Vocational/ Technical High Schools" (2008). Dissertations. 1711.

https://digitalcommons.andrews.edu/dissertations/1711

https://dx.doi.org/10.32597/dissertations/1711

This Dissertation is brought to you for free and open access by the Graduate Research at Digital Commons @ Andrews University. It has been accepted for inclusion in Dissertations by an authorized administrator of Digital Commons@ Andrews University. For more information, please contact repository@andrews.edu. 


\section{ABSTRACT}

THE RELATIONSHIP BETWEEN COLLECTIVE-EFFICACY AND STUDENT ACHIEVEMENT IN VOCATIONAL/TECHNICAL HIGH SCHOOLS

by

Rosemary Tralli

Chair: James A. Tucker 


\section{ABSTRACT OF GRADUATE STUDENT RESEARCH}

Dissertation

Andrews University

School of Education

\section{Title: THE RELATIONSHIP BETWEEN COLLECTIVE-EFFICACY AND STUDENT ACHIEVEMENT IN VOCATIONAL/TECHNICAL HIGH SCHOOLS}

Name of researcher: Rosemary Tralli

Name and degree of faculty chair: James A. Tucker, Ph.D.

Date completed: May 2008

\section{Purpose}

The impact of teachers' efficacious beliefs on achievement in technical high schools required further investigation. This study examined the collective-efficacy beliefs of academic and trade departments in 17 Connecticut technical high schools and the relationship between those beliefs and student achievement.

\section{Method}

The collective-efficacy beliefs of 730 teachers were measured through use of the Collective Teacher-Efficacy Belief Scale. Perceptions of influence over instruction, discipline, and overall efficacy were obtained. A sample of 2,592 students was used to obtain achievement data in mathematics, science, reading, and writing on the Connecticut 
Academic Performance Test. Multiple regression analysis was used to determine correlations between collective-efficacy beliefs and achievement. A confirmatory factoranalysis was completed to assure the reliability of the test instrument.

\section{Results}

A significant relationship was evidenced between teacher perceptions of collective-efficacy and student achievement in mathematics, science, reading, and writing. Achievement in math and science were most effectively predicted by the collective teacher beliefs around school discipline. Reading and writing achievement were most effectively predicted by the overall perceptions of teachers' collectiveefficacy. Additionally, the results supported the relationship between socioeconomic status of schools and student achievement. Collective-efficacy beliefs about student discipline were lower at schools that served students of lower socioeconomic status. The Collective-Efficacy Belief Scale met confirmatory factor analysis examination. All but one item loaded under expected components of Instruction and Discipline.

\section{Conclusions}

The collective-efficacy beliefs of educators were important considerations as school leaders develop safe, orderly, and productive learning environments. Since efficacy around behavior was particularly influential, leaders need to ensure disciplinary control. Organizations need to provide explicit opportunities for teachers and administrators to measure and develop their sense of efficacy and beliefs about student learning as a key component of reflective school practice. 
Andrews University

School of Education

THE RELATIONSHIP BETWEEN COLLECTIVE-EFFICACY AND STUDENT ACHIEVEMENT IN VOCATIONAL/TECHNICAL HIGH SCHOOLS

\author{
A Dissertation \\ Presented in Partial Fulfillment \\ of the Requirements for the Degree \\ Doctor of Philosophy
}

by

Rosemary Tralli

May 2008 
(C) Copyright by Rosemary Tralli 2008

All Rights Reserved 


\section{THE RELATIONSHIP BETWEEN COLLECTIVE-EFFICACY AND STUDENT ACHIEVEMENT IN VOCATIONAL/TECHNICAL HIGH SCHOOLS}

A dissertation

presented in partial fulfillment of the requirements for the degree

Doctor of Philosophy

by

Rosemary Tralli

APPROVAL BY THE GOMMITTEE:

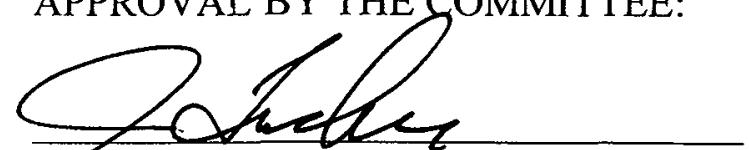

Chair: James A. Tucker

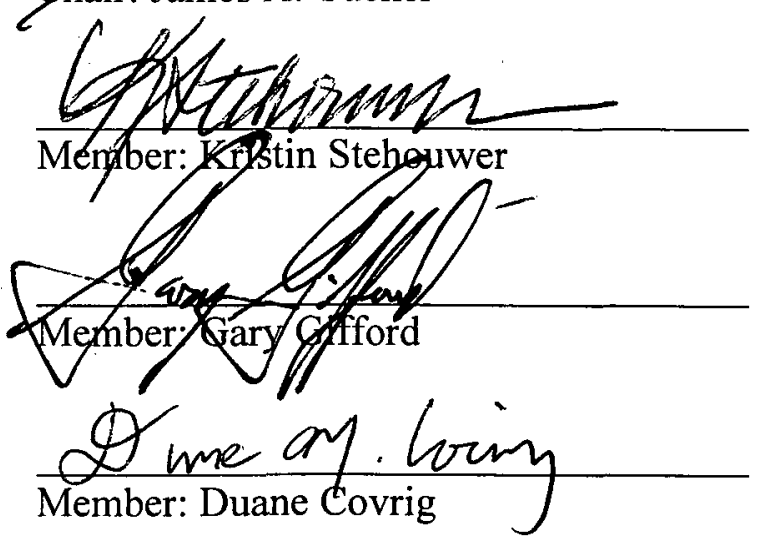

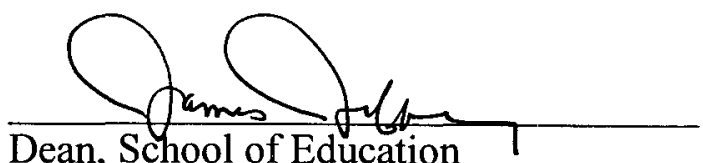

James Jeffery

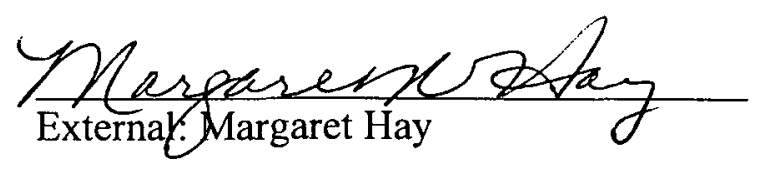

$\frac{5 / 09 / 08}{\text { Date approved }}$ 


\section{TABLE OF CONTENTS}

LIST OF TABLES $\ldots \ldots \ldots \ldots \ldots \ldots \ldots \ldots \ldots \ldots \ldots \ldots$ vii

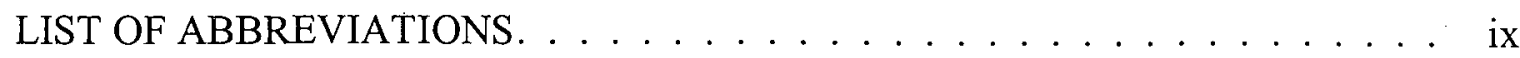

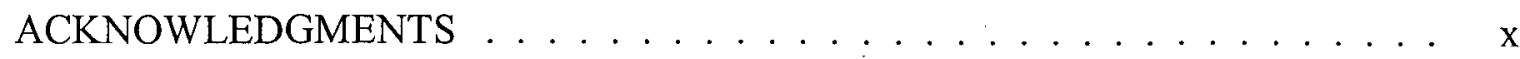

Chapter

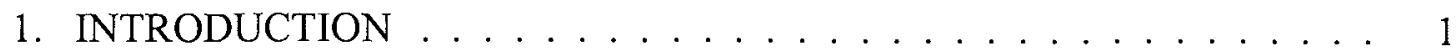

Background to the Study . . . . . . . . . . . . . . . 1

Leadership in Education Reform Efforts . . . . . . . . . . . . . 1

Teacher Qualifications to Support Instructional Practice. . . . . . . 2

The Role of Efficacious Beliefs in Quality Instruction . . . . . . . . 4

Statement of the Problem . . . . . . . . . . . . . . . 5 5

Purpose of the Study . . . . . . . . . . . . . . . . . . 6

Importance of the Study. . . . . . . . . . . . . . . . . . . . . 6

Research Questions . . . . . . . . . . . . . . . . . . 8

Assumptions. . . . . . . . . . . . . . . . 8

Theoretical Base of the Study. . . . . . . . . . . . . . . . . 9

Definition of Terms . . . . . . . . . . . . . . . . . . 10

Delimitations of the Study . . . . . . . . . . . . . 11

Limitations of the Study. . . . . . . . . . . . . . . . . 11

General Methodology . . . . . . . . . . . . . . . . . . 12

Organization of the Study . . . . . . . . . . . . . . . 12

2. REVIEW OF THE LITERATURE . . . . . . . . . . . . . . . . 14

Introduction . . . . . . . . . . . . . . . . . . 14

Historical Perspective on the Social Cognitive Theory. . . . . . . 15

Human-Agency Definition . . . . . . . . . . . . . . . . 15

Causal Models of Human-Agency . . . . . . . . . . . . . 15

Primary Features of Human-Agency . . . . . . . . . . . . . . . 17

Intentionality . . . . . . . . . . . . . 17

Forethought . . . . . . . . . . . . . . . 17

Self-Reactiveness . . . . . . . . . . . . . . . . . . . 17

Self-Reflectiveness . . . . . . . . . . . . . . . . 18

Social Cognitive Theory Underpinnings . . . . . . . . . . . . 18 
Behavior Theory Detractors to Social Cognitive Theory. . . . . . . . 20

Sources of Efficacy Development . . . . . . . . . . . . 21

Social Persuasion . . . . . . . . . . . . . . . . 21

Vicarious Experiences . . . . . . . . . . . . . . . . . . . 22

Physiological Experiences . . . . . . . . . . . . . . . . 22

Mastery Experiences . . . . . . . . . . . . . . . . . . . . 22

Forms of Human-Agency . . . . . . . . . . . . . . . . . . 23

Personal-Agency . . . . . . . . . . . . . . . 24

Proxy-Agency . . . . . . . . . . . . . . . . . 24

Collective-Agency . . . . . . . . . . . . . . . . . . . 24

Social Cognitive Model of Self-Regulation. . . . . . . . . . . . 25

Impact of Efficacious Beliefs . . . . . . . . . . . . . . . . . 25

Social Cognitive Career Theory. . . . . . . . . . . . . . . . . 27

Gender and Social Cognitive Career Theory . . . . . . . . . . 28

Student Populations and Social Cognitive Career Theory . . . . . 28

Teacher-Efficacy . . . . . . . . . . . . . . . . . . . . . . . . . . . . . 29

Teacher-Efficacy Instrumentation . . . . . . . . . . . . 30

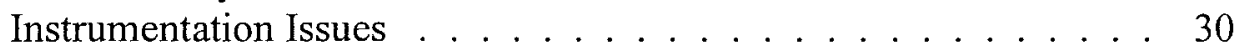

Constructs for Instrumentation Development . . . . . . . . . . 30

Historical Review of Instruments . . . . . . . . . . . . . . . . . 31

RAND Scale. . . . . . . . . . . . . . . . . . . . 31

Teacher-Efficacy Scale . . . . . . . . . . . . . . 32

Collective-Efficacy Constructs . . . . . . . . . . . . . . . . 33

Relationship of Collective-Efficacy and Education. . . . . . . . . 34

Relationship of Collective-Efficacy and Change Processes . . . . . . . 35

Collective-Efficacy Instrumentation . . . . . . . . . . . . . 37

Summary . . . . . . . . . . . . . . . . 38

3. METHODOLOGY . . . . . . . . . . . . . . . . . . . . . . 39

Introduction . . . . . . . . . . . . . . . . . . . . . . 39

Identification of Variables . . . . . . . . . . . . . . . . 39

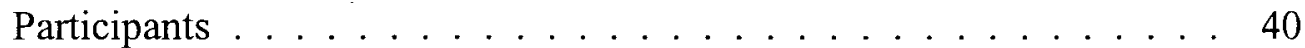

Population and Sample for the Independent Variable . . . . . . . 40

Population and Sample for the Dependent Variables . . . . . . . . 40

Sample Selection . . . . . . . . . . . . . . . . . 40

Instrumentation . . . . . . . . . . . . . . . . . . . 42

Collective Teacher-Efficacy Belief Scale (CTEBS) . . . . . . . . 42

Instrument Selection . . . . . . . . . . . . . . 42

Instrument Description . . . . . . . . . . . . . . . . 42

Instrument Administration . . . . . . . . . . . . . . . . 43

Instrumentation Characteristics . . . . . . . . . . . . . . . . 43

Connecticut Academic Performance Test. . . . . . . . . . . . . . . 43

Instrument Selection . . . . . . . . . . . . . . . . . 43

Instrument Description . . . . . . . . . . . . . . . . . . . . . 44

Instrument Administration . . . . . . . . . . . . . . . . . 44 
Instrumentation Characteristics . . . . . . . . . . . . . . 45

Null Hypotheses. . . . . . . . . . . . . . . . . . . . . . . 45

Null Hypothesis $1 \ldots \ldots$. . . . . . . . . . . . . . . . . 45

Null Hypothesis 2 . . . . . . . . . . . . . . . . . . . 45

Null Hypothesis $3 \ldots \ldots \ldots$

Null Hypothesis $4 \ldots \ldots \ldots$

Data Analysis . . . . . . . . . . . . . . . . . . 46 46

Availability of Raw Data . . . . . . . . . . . . . . . . . . . . 48

Participant Rights Protection . . . . . . . . . . . . . 48

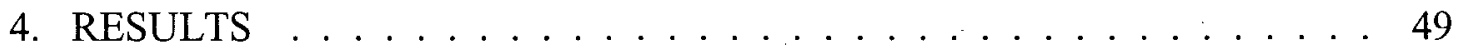

Introduction . . . . . . . . . . . . . . . . . . . . . 49

Description of the Samples . . . . . . . . . . . . . . . . . . 49

Collective-Efficacy Sample. . . . . . . . . . . . . . . . . . . . 49

Student Achievement Sample. . . . . . . . . . . . . . . 50

Hypotheses . . . . . . . . . . . . . . . . . . . 53

Null Hypothesis $1 \ldots \ldots \ldots$. . . . . . . . . . . . . . 53

Null Hypothesis $2 \ldots \ldots \ldots$

Null Hypothesis $3 \ldots \ldots \ldots$

Null Hypothesis $4 \ldots \ldots$. . . . . . . . . . . . . . . . . . 53

Preliminary Statistical Analysis. . . . . . . . . . . . . . . . . . 54

Collective-Efficacy Variables. . . . . . . . . . . . . . . . 54

Academic Performance Variables. . . . . . . . . . . . . . . 57

Pearson Product-Moment Correlations . . . . . . . . . . . . . . . 61

Primary Statistical Analysis. . . . . . . . . . . . . . . . . 65

Hypothesis Testing . . . . . . . . . . . . . . . . 6 66 66

Null Hypothesis $1 \ldots \ldots \ldots 6$

Null Hypothesis $2 \ldots \ldots \ldots 7$

Null Hypothesis $3 . \ldots \ldots$

Null Hypothesis $4 \ldots \ldots$

Summary . . . . . . . . . . . . . . 70

5. SUMMARY, CONCLUSIONS, IMPLICATIONS, AND

RECOMMENDATIONS . . . . . . . . . . . . . . . 72

Introduction . . . . . . . . . . . . . . . . . . 72

Purpose of the Study . . . . . . . . . . . . . . . . . . 73

Overview of the Literature Review . . . . . . . . . . . . . . . . 73

Research Questions . . . . . . . . . . . . . . . . . . . . 75

Research Design. . . . . . . . . . . . . . . . . . . . . 75

Summary of Findings . . . . . . . . . . . . . . . . . 76

Conclusions and Implications. . . . . . . . . . . . . . . 77

Recommendations. . . . . . . . . . . . . . . . . . 78

Recommendations for Further Research . . . . . . . . . . . 78

Recommendations for School Leaders . . . . . . . . . . . . 80 
Appendix

A. CONNECTICUT TECHNICAL HIGH SCHOOLS LESSON PLAN . . . . . 83

B. CONNECTICUT TECHNICAL HIGH SCHOOL SYSTEM

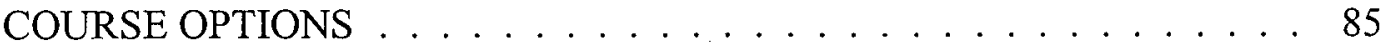

C. TEACHER CERTIFICATION REQUIREMENTS AND APPLICATION . . 90

D. CONNECTICUT TECHNICAL HIGH SCHOOL SYSTEM APPLICATION FOR ADMISSION . . . . . . . . . . . . . . . . . . 97

E. POLICY REGARDING GRADUATION REQUIREMENTS AND BASIC SKILL REQUIREMENTS FOR GRADUATION . . . . . . . . . . . . . . . 103

F. COLLECTIVE EFFICACY BELIEF SCALE . . . . . . . . . . . . . . 109

G. CONNECTICUT ACADEMIC PERFORMANCE TEST (CAPT) . . . . . . 111

H. DESCRIPTION OF PERFORMANCE LEVELS . . . . . . . . . . . . . . 113

I. CONNECTICUT ACADEMIC PERFORMANCE TEST (CAPT) ADMINISTRATION . . . . . . . . . . . . . . . . 116

REFERENCE LIST . . . . . . . . . . . . . . . . . . . . . . . 119

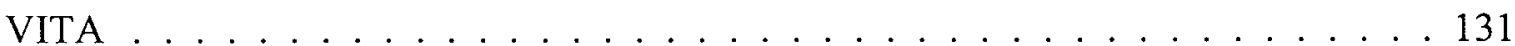




\section{LIST OF TABLES}

1. Number of Teachers by Participating School . . . . . . . . . . . 51

2. Number of Students by Participating School . . . . . . . . . . . . . 52

3. Descriptive Statistics on Collective-Efficacy Variables . . . . . . . . 55

4. Collective-Efficacy Sample Normality Descriptors . . . . . . . . . . . 56

5. ANOVA Title 1 Relationship to Collective-Efficacy Beliefs on Instruction . . 57

6. ANOVA Title 1 Relationship to Collective-Efficacy Beliefs on Discipline . . 57

7. Means and Standard Deviations on Achievement Variables . . . . . . . . . 58

8. Achievement Sample Normality Descriptors . . . . . . . . . . . . . . 58

9. ANOVA Title 1 Relationship to CAPT Mathematics Performance . . . . . . 59

10. ANOVA Title 1 Relationship to CAPT Science Performance . . . . . . . . . 60

11. AIJOVA Title 1 Relationship to CAPT Reading Performance . . . . . . . . . 60

12. ANOVA Title 1 Relationship to CAPT Writing Performance . . . . . . . 61

13. Inter-correlations of Predictor and Criterion Variables . . . . . . . . . . 62

14. CTEBS Total Variance Explained $\ldots \ldots \ldots \ldots 63$

15. CTEBS Rotated Component Matrix _ . . . . . . . . . . . . 64

16. Hierarchical Regression Analysis of a Set of Predictor Variables Explaining the Variance in Mathematics Score on the CAPT $(N=730) \ldots \ldots . .666$

17. Hierarchical Regression Analysis of a Set of Predictor Variables Explaining the Variance in Science Score on the CAPT $(N=730) \ldots \ldots \ldots$. . . 67

18. Hierarchical Regression Analysis of a Set of Predictor Variables Explaining the Variance in Reading Score on the CAPT $(N=730) \ldots \ldots \ldots 68$ 
19. Hierarchical Regression Analysis of a Set of Predictor Variables Explaining the Variance in Writing Score on the CAPT $(N=730) \ldots \ldots$ 


\section{LIST OF ABBREVIATIONS}

CAPT Connecticut Academic Performance Test

CE Collective Efficacy

CTEBS Collective Teacher-Efficacy Belief Scale

GTE General Teaching Efficacy

HOUSSE High Objective, Uniform State Standard of Evaluation

NCLB No Child Left Behind Act of 2001

PTE Personal Teaching Efficacy

RAND Research and Development Corporation

SCT Social Cognitive Theory

SCCT Social Cognitive Career Theory

TES Teacher Efficacy Scale 


\section{ACKNOWLEDGMENTS}

I dedicate this work to my loving family. To my husband, Tom, I thank you for your encouragement, excitement, and assistance on all worldly tasks to keep me focused. To my children, Justin and Melissa, your own life journeys during this time inspired me as I watched you grow into adulthood. I was continually motivated by the unwavering faith and encouragement of my mother, sister, and brother-in-law.

I extend my deepest thanks to my Chairperson, Dr. James Tucker; my committee members Dr. Kristin Stehouwer, Dr. Duane Covrig, and Dr. Gary Gifford; and to my advisor, Dr. Marianne Kirner, for your expertise and support. I thank the Andrews University Leadership Program for this tremendous scholarship experience.

I completed this research due to the permission and support of Connecticut Technical High School administration. I hold deepest gratitude to Dr. Abigail Hughes and Dr. Anne Druzolowski for allowing me to conduct this research and for their continual support throughout the journey. 


\section{CHAPTER 1}

\section{INTRODUCTION}

\section{Background to the Study}

\section{Leadership in Education Reform Efforts}

In efforts to increase student achievement, current United States federal mandates prompt unprecedented levels of state and local accountability (Reeves, 2004). School leaders across the country face enormous challenges as "those in charge are saddled with enormous and growing burdens, including insufficient budgets; bureaucratic inertia; political conflicts; and a torrent of local, state and federal mandates" (Weiss, 2005, p. 1).

Under the No Child Left Behind (NCLB) Act of 2001, states had to indicate how they would close the achievement gap for diverse student groups (No Child Left Behind Act, 2001). Schools developed and published report cards that informed the public of their annual progress in improving student outcomes. Schools that did not make adequate yearly progress would be restructured (U.S. Department of Education, 2005).

Additionally, every state needed to ensure that all students are taught by highly qualified teachers. Although the No Child Left Behind Act of 2001 defined "highly qualified" status through certification processes, many other teacher factors were recognized as critical to student achievement (U.S. Department of Education, 2006).

School reform was a leading area of investigation over the past 3 decades (Elmore, 1990). Two notable initiatives in these reforms are illustrative of the ineffective 
efforts made in this era. In 1983, the National Commission on Excellence in Education report entitled $A$ Nation at Risk raised deep concerns over the mediocrity of society regarding educational practices in the United States (U.S. Department of Education, 1983). For 5 years after that report, initiatives under the Excellence Movement researched and encouraged new avenues to increase funds and services for schools across the country; these efforts, however, failed to result in notable student achievement advances (Elmore, 1990). In 1989, another notable initiative was introduced to support student achievement. The Goals 2000: Educate America Act included seven goals to support student achievement with a focus on the use of site-based processes to actualize these goals (Goals 2000: Educate America Act, 1994). Despite efforts to empower local schools through this movement, there was little evidence of student growth (Guskey \& Passaro, 1994; WestEd, 2003). Guskey asserts, "The gap in education between our knowledge base and general practice remains depressingly large" (Guskey \& Passaro, 1994, p. 6).

\section{Teacher Qualifications to Support Instructional Practice}

Teacher qualification is a primary component in federal efforts to increase student achievement under the No Child Left Behind Act of 2001 (U.S. Department of Education, 2006). All states were required to ensure that teachers were highly qualified by the 2005-2006 school year. To achieve this goal, states were required to define the extent to which students are taught by highly qualified teachers, develop goals and plans to increase teacher qualifications, and publicize their efforts in meeting this requirement (No Child Left Behind Act, 2001). To be deemed highly qualified under the No Child Left Behind Act of 2001, teachers needed to (a) have a bachelor's degree, (b) have full 
state certification or licensure, and (c) prove that they know each subject they teach. New teachers in middle schools and high schools needed to show evidence of proficiency in their subject matter by (a) earning a major in the subject they teach, (b) earning credits equivalent to a major in the subject, (c) passing a state-developed test, (d) earning an advanced certification from the state, or (e) earning a graduate degree (No Child Left Behind Act, 2001).

Current teachers were able to demonstrate proficiency through a High, Objective, Uniform State Standard of Evaluation (HOUSSE) that might be developed by individual states; evidence of competence could be indicated through a combination of teaching experience, professional development, and knowledge in the subject acquired throughout their careers (No Child Left Behind Act, 2001).

Current school reforms continue to explore the interplay between teacher practices, school infrastructure supports, curriculum, and assessment (Elmore, 2006). Under the No Child Left Behind Act of 2001 and the Individuals with Disabilities Act of 2004 , schools were expected to identify and implement programs that are grounded in scientifically based research. "Scientifically based research" involved the application of rigorous, systematic, and objective procedures to obtain reliable and valid knowledge relevant to education activities and programs (No Child Left Behind Act, 2001). Teachers were expected to learn and use these practices to improve student achievement (Johnson \& Stevens, 2006). As with past reform efforts, however, teachers' implementation of effective instructional techniques was inconsistent and not readily sustained (Hall \& Hord, 2006). 
The Role of Efficacious Beliefs in Quality Instruction

Teacher-efficacy research has contributed important information about the relationship between instructional perceptions and instructional quality (Pajares, 1997). Linked to the constructs of Social Cognitive Theory, perceived self-efficacy was defined as people's judgments of their capabilities to organize and execute courses of action required to attain designated types of performances. It was concerned not with the skills one has but with judgments of what one can do with whatever skills one possesses (Bandura, 1986, p. 391).

Teachers' self-efficacy ratings were predictive of student achievement (Weber \& Omotani, 1994). Teachers with stronger efficacy beliefs developed more challenging instructional activities and instructional goals for their students (Brophy, 1986; Burton, 1995; Pajares, 1996; Ross, 1994). Teachers with stronger efficacy levels were more likely to help students to achieve their end-of-year goals (Allinder, 1995). Efficacy was linked to teachers' levels of professional commitment (Coladarci, 1992).

Information on the relationship between school-wide collective-efficacy and student achievement was also important in examining teacher quality (Tagger, 2002; Tschannen-Moran \& Barr, 2004; Walumbwa, Wang, Lawler, \& Shi, 2004). Collectiveefficacy referred to each person's assessment of the group's joint capacity to perform jobrelated behaviors (Riggs, Warka, Babasa, Betancourt, \& Hooker, 1994). Greater student achievement was noted in schools with high collective teacher-efficacy (Bandura, 2000; Goddard \& Goddard, 2001; Goddard, LoGerfo, \& Hoy, 2004). Teacher involvement in school-based decision-making was linked to collective-efficacy (Goddard, Hoy, \& Woolfolk Hoy, 2004; Ross \& Gray, 2004). The direct and indirect influences of efficacy 
on other factors that contributed to student achievement were important areas for future exploration (Goddard, Hoy, et al., 2004).

\section{Statement of the Problem}

Federal and state governments were very interested in finding ways to increase student achievement. Despite governmental mandates for high-quality instruction, student achievement had not increased to proficient levels. Toward that end, Elmore (2006) indicated, "Rigorous and engaging instruction remains all too rare across schools of all types" (p. 3). When analyzing the connections between teachers' collective-efficacy beliefs and student achievement, Mawhinney, Haas, and Wood (2005) stated, "Significantly for school districts faced with the sanctions imposed by NCLB as a result of lower school performance, once established, collective efficacy beliefs are hard to change" (p. 8).

Teacher implementation of research-based instructional practices was integral to student achievement, yet teachers were often perceived to be resistant to school improvement efforts. This study examined one area of resistance by identifying the impact of efficacious beliefs on teacher instruction. Perceived collective-efficacy influenced teachers' decisions to implement instructional pedagogy (Tschannen-Moran \& Barr, 2004). More research was needed to determine how teachers learn new instructional approaches and on the work conditions that impact teacher acquisition of new skills (Elmore, Peterson, \& McCarthey, 1996).

Mawhinney et al. (2005) indicated the need for further research on the effects of collective efficacy and sources of collective-efficacy in professional learning communities. Pajares (1996) indicated the need for research to augment the connection 
between efficacy and specific critical variables that may increase achievement. Toward that end, additional research may clarify the interplay between collective-efficacy and student achievement within settings.

\section{Purpose of the Study}

This study explored the relationship between collective-efficacy beliefs of teachers and student achievement. Specifically, this study examined the collectiveefficacy beliefs of academic and trade departments in 17 Connecticut technical high schools and the relationship between those beliefs and student achievement on the Connecticut Academic Performance Test. The study provides important information to instructional leaders about change mechanisms that promote student growth by unveiling associations between key school factors. It is particularly relevant in that it studies these associations at vocational-technical high-school settings. Lindley (2006) noted the importance of ongoing research that investigates the relationship of efficacy to vocational outcomes. As a result of this research, instructional leaders in vocational-technical high schools may apply new knowledge of the relationships between collective-efficacy and student achievement to create stronger professional learning environments in their schools.

\section{Importance of the Study}

This research contributes new information about the relationship between collective-efficacy and student achievement within vocational-technical high-school settings. Although the direct relationship between collective-efficacy and student achievement has been clearly established (Bandura, 2001), the predictive value of 
collective-efficacy to aspects of student achievement in vocational-technical high schools is not well documented in the literature. Vaz (2006) noted, "There is a minimal amount of research regarding predictors of success in academic performance in vocational education at the high school level" (p. 21).

Pajares (1996) indicated,

When efficacy beliefs are globally assessed and/or do not correspond with the critical tasks with which they are compared, their predictive value is diminished or can even be nullified; and when efficacy assessments are tailored to the critical task, prediction is enhanced. (p. 6)

This study provides important information about leadership mechanisms that promote student growth by unveiling direct and indirect associations between key school factors within a vocational-technical high-school setting.

Few studies made a priori predictions about what organizational properties were related to school effectiveness or student achievement, and that remains the case today. Even fewer studies described the processes and mechanisms that link school properties to student achievement (Hoy, Smith, \& Sweetland, 2002, p. 186).

The identification of critical relationships between collective-efficacy and achievement would provide such helpful information to school leaders. Ross, Hogaboam-Gray, and Gray (2004) indicated,

School processes that promoted teacher ownership of school directions (shared school goals, school-wide decision making, fit of plans with school needs, and empowering principal leadership) exerted an even stronger influence on collective teacher efficacy than prior student achievement. (p. 1)

Analysis of the relationship between these factors within school settings may promote more substantive professional development (Guskey, 2000) and professional learning-communities (Hall \& Hord, 2006) which, in turn, may promote greater student 
achievement and school-based leadership. This research has pragmatic implications in that the instrumentation is readily accessible by all school leaders. The current drive in schools for data-driven decision-making makes this research particularly feasible and important (Reeves, 2004).

\section{Research Questions}

1. Is there a relationship between the degree of perceived collective-efficacy and student achievement in mathematics?

2. Is there a relationship between the degree of perceived collective-efficacy and student achievement in writing?

3. Is there a relationship between the degree of perceived collective-efficacy and student achievement in science?

4. Is there a relationship between the degree of perceived collective-efficacy and student achievement in reading?

\section{Assumptions}

I made the following assumptions in this study:

1. Student achievement is dependent on teacher implementation of sound instructional pedagogy.

2. Teachers within vocational-technical settings have unique school characteristics that may impact implementation of sound instructional pedagogy.

3. Teachers control their decisions to use instructional pedagogy.

4. Research-based instructional innovations will serve to increase student achievement if implemented by teachers. 
5. There will be no change in outcomes until new practices are implemented (Hall \& Hord, 2006).

6. Socioeconomic status accounts for variances in student achievement.

\section{Theoretical Base of the Study}

The theoretical base of this study is founded in Social Cognitive Theory (Bandura, 1986). Primary constructs of Social Cognitive Theory include the following:

1. All persons are capable of self-regulated behaviors, or human-agency, in that they can follow an intended course of action.

2. A person's perceptions about his/her capabilities are defined as self-efficacy. Self-efficacy relates to perceptions of competence rather than actual competence levels.

3. Self-efficacy perceptions are high predictors of an individual's behaviors and of changes in behaviors. Perceptions are higher predictors of behavior than actual capabilities.

4. Self-efficacy is a task-specific perception and is therefore different from other self-concepts such as self-concept and self-esteem.

5. The behavioral choices that an individual makes are influenced by the strengths of his or her efficacy beliefs.

6. Self-efficacy beliefs are future-oriented conclusions about the individual's capabilities to act in specific situations or contexts. 


\section{Definition of Terms}

The contextual definitions of key terms used in this study are provided in this list.

Achievement gap: The disparity between the academic performance of different groups of students largely along economic, racial, and ethnic lines.

Collective teacher-efficacy: Teacher perceptions that the faculty, as a group, can plan and implement procedures that will positively affect their students (Goddard, Hoy, et al., 2004).

Concerns: "The composite representation of the feelings, preoccupation, thought, and consideration given to a particular issue or task" (Hall \& Hord, 2006, p. 61).

Disciplinary examples: Suspension/expulsion rates, detentions, and number of times students are sent out of class.

Highly qualified teachers: To be deemed highly qualified, teachers must have (a) a bachelor's degree, (b) full state certification or licensure, and (c) prove that they know each subject they teach (NCLB).

Human-agency: All persons are capable of self-regulated behaviors.

Innovation: Any process, product, program or idea that is the focus of change.

Personal-efficacy: A person's perceptions about his/her capabilities and relates to perceptions of competence rather than actual competence levels.

Self-efficacy: A person's perceptions about his/her capabilities and relates to perceptions of competence rather than actual competence levels.

Social Cognitive Theory: A theory developed by Albert Bandura stemming from Social Learning Theory; a person's behavior is a result of the interaction of personal factors, behavior, and the environment. 
Teacher-efficacy: "Teacher's judgments of his or her capabilities to bring about desired outcomes of student engagement and learning, even among those students who may be difficult or unmotivated" (Tschannen-Moran \& Woolfolk Hoy, 2001, p. 187).

\section{Delimitations of the Study}

This study was delimited to teachers within the Connecticut Technical HighSchool District in Connecticut. The sample included trade and academic teachers who worked at the secondary school level. Due to the large sample of teachers across the district, data were not collected on other school personnel such as counselors, administrators, tutors, paraprofessionals, consultants. Parents and students were not included in the sample.

\section{Limitations of the Study}

Due to the vocational components and course schedules of the school program, teachers within this system were not necessarily representative of teachers within more traditional high-school settings. The academic teachers involved in this study worked under unique circumstances. Despite the universal requirements for student achievement under No Child Left Behind, these teachers met with students for half of the number of school days that teachers from non-vocational settings would meet for instructional delivery of academic content. This organizational system was unique. No other school district in the United States used an identical model of course scheduling, program offerings, or admissions. Therefore, the generalizability of this study may be limited. 


\section{General Methodology}

In this study, I used multiple regression techniques to examine the relationships between teachers' collective-efficacy (independent variable) and student achievement (dependent variable). The sample I used to obtain data for the independent variable included teachers within academic and trade departments from 17 technical high schools. I measured the independent variable through use of a collective-efficacy questionnaire. Student achievement scores from the same schools provided my data for the dependent variable. I included the composite test scores for student achievement in science, math, writing, and reading on the Connecticut Academic Performance Test. I discuss specific instrumentation and statistical measures in chapter 3 .

\section{Organization of the Study}

Collective-efficacy beliefs of teachers affect professional learning environments and meaningful change efforts (Dellinger, 2001). Strong collective-efficacy of a group of teachers can interfere with reform processes (Collins, 2001) and with student achievement. Pajares (1996) noted,

It would be useful to develop insights about how and why differing interpretations of similar attainments and from similar sources result in different beliefs, as well as how inaccurate self-perceptions are developed and why they can persist even in the face of subsequent successes and strong performance attainments. (p. 544)

My study contributes to the existing research by examining the relationships between collective-efficacy and student achievement in vocational-technical high-school settings.

The remaining chapters of this study include the following information: Chapter 2 provides a review of the literature on school-reform efforts and the role of efficacious beliefs on student achievement. Historical background, instrument descriptors, and 
relevant research on efficacy are included. Chapter 3 describes the quantitative methodology of the study. The research design, test instrumentation, and population are defined. Chapter 4 presents the study outcomes including an analysis of the data and overall findings of the study. Chapter 5 provides a summary of the study, its implications, and recommendations for future research. 


\section{CHAPTER 2}

\section{REVIEW OF THE LITERATURE}

\section{Introduction}

The literature I review and report in this chapter serves these primary purposes: (a) to provide a historical perspective on the development and use of Social Cognitive Theory as the theoretical construct for explaining collective-efficacy (independent variable); and (b) to exemplify the relationship of efficacy research to student achievement (dependent variable).

I searched the literature through use of computerized databases. I acquired access to these databases through the State Education Resource Center Library in Connecticut. Keywords I used for this search included efficacy, teacher-efficacy, collective-efficacy, motivation, change, innovation, student achievement, Bandura, and Social Cognitive Theory. I sequenced various permutations of these key words to gain research sources. Initially, I collected and reviewed abstracts for relevance. I acquired full-text articles for abstracts that appeared to contain suitable content, sampling, instrumentation, and methodology. I used article references to investigate additional studies on key topics. Key sources included full research studies by primary sources. I collected information and organized that information in an Endnotes Version 9.1 Library.

I organized this literature review into two main categories. A sequential process for understanding research development in collective-efficacy and its impact on student 
achievement is addressed through my division of main headings. The first section provides a historical context. The evolution of Social Cognitive Theory as the foundation of collective-efficacy research is described. I present elaborated definitions of terms and processes within the constructs of Social Cognitive Theory. The second section of this review centers on the research base of teacher-efficacy and student achievement. I have reviewed specific research findings. I provide a discussion of instrumentation issues and research reviews. I present instrumentation types and issues. I have concluded this chapter with a summary statement. My conclusion redefines the critical aspects of research that supported this study.

\section{Historical Perspective on the Social Cognitive Theory}

\section{Human-Agency Definition}

The construct of human-agency was critical to the development of efficacy research. Human-agency was defined within the context of this study as "the capacity to exercise control over one's own thought processes, motivation, and actions" (Bandura, 1989a, p. 1175).

\section{Causal Models of Human-Agency}

Reese, Reese, and Tausner (1995) reported that roots of the causal model for human agency were founded in the psychodynamic model. This deterministic theory held that all human behavior results from underlying psychological forces that may or may not be within a person's realm of conscious awareness. These psychological forces were defined as dynamic, since they interact with one another to generate behavior, 
thoughts, and emotions. Early life experiences were considered primary motivators for behaviors throughout life (Freud, 1989/1930).

Behavioral-change therapy in the 1950 s relied heavily on the psychodynamic model (Stricker \& Gold, 2004). By the 1960s, new theories of human-agency emerged. These models moved toward the exploration and consideration of external forces on agency and behavior. Primary conceptual models included mechanical agency and emergent interactive-agency change (Pajares, 1997).

Mechanical agency viewed human behavior and subsequent changes in behavior as conditional to external forces put upon them (Skinner, 1938). Operant-behaviortheory conditioning provided an example of mechanical agency (Skinner, 1958). Under this theory, operant conditioning was a result of the interplay between behaviors and reinforcing outcomes. A behavior that was followed by positive reinforcement would likely be repeated in the future under similar circumstances, whereas a behavior followed by negative reinforcement may not be repeated. Behaviors were commonly learned and reinforced through external molding (Pavlov, 1927). Other popular stimulus-response models within this field included those of Pavlov and Watson. The emphasis on observation behaviors that could be quantitatively measured was the focus of this theoretical base (Pavlov, 1927; Watson, 2006).

Emergent interactive-agency stressed the interactive impact of modeling, selfregulation, and external incentives on behavior (Bandura, 1997). Social Cognitive Theory subscribed to the emergent-interactive model of human-agency. Under this construct, human-agency "addresses the issue of what is means to be human" (Bandura, 2001, p. 6). 


\section{Primary Features of Human-Agency}

Bandura (1997) defined four domains of human-agency: intentionality, forethought, self-reactiveness, and self-reflectiveness. The importance of each feature to research on collective-efficacy is described in this section.

\section{Intentionality}

The concept of intentionality involved deliberate planning for future actions. A key construct of intentionality was the "proactive commitment to bringing them about" (Bandura, 2001, p. 6). Willful planning was based on one's knowledge of the intended act and of the act's expected outcome. Human intentionality provided a basis for understanding how persons control their choice of actions based on perceived purposes or outcomes of these actions (Bandura, 1997).

\section{Forethought}

Motivations to perform intended actions and self-guidance while completing intended astions were components of forethought (Bandura, 2001). The ability to direct one's own actions regardless of external influences was a primary component of this feature of agency.

\section{Self-Reactiveness}

This feature of agency provided for ways to enact intended plans (Bandura, 2001). Components of this feature included (a) deliberate shaping of opportunities for plan execution, (b) motivating oneself through execution, and (c) manipulating environmental circumstances. Governing functions included self-monitoring, use of personal standards, morals, and ethics to guide plan enactment, and use of self-feedback to make alterations 
in plan delivery. This feature illustrated the interplay of factors as one decides to move from intentions to actual fulfillment of an intended plan of action.

\section{Self-Reflectiveness}

The ability to evaluate one's own performance was a primary feature of humanagency (Bandura, 2001). This element moved beyond planning, delivery, and manipulation of environmental conditions. The metacognitive ability to evaluate the outcomes of one's actions, motives, and values was important to self-regulation of behaviors. Efficacious belief was an integral component of this construct and moves the concept of human-agency into a broad field of research. Bandura (2001) indicated, "Efficacy beliefs are the foundation of human-agency" (p. 10). Self-efficacy involved the beliefs persons hold regarding their personal levels of control over internal and external influences.

\section{Social Cognitive Theory Underpinnings}

In 1987, Albert Bandura proposed a social cognitive theory utilizing humanagency as a foundational underpinning. Primary constructs of Social Cognitive Theory include:

1. All individuals were capable of human-agency or the premeditated pursuit of courses of action. They could be proactive, organize themselves, and self-regulate their behaviors.

2. The beliefs that individuals have about their capacities were their perceptions of self-efficacy. It was important to note that efficacy related to an individual's perceptions of competence rather than to actual levels of competence. 
3. Self-efficacy perceptions were high predictors of an individual's behaviors and of changes in behaviors. Bandura (1989a) indicated that perceptions are higher predictors than actual capabilities and that either over- or underestimating may influence how well individuals apply their capabilities.

4. Self-efficacy was a task-specific perception and was therefore different from other cognitions such as self-concept and self-esteem. "Self-esteem usually is considered to be a trait reflecting an individual's characteristic affective evaluation of self (e.g., feelings of self-worth or self-liking). By contrast, self-efficacy is a judgment about task capability that is not inherently evaluative" (Gist \& Mitchell, 1992, p. 185).

5. The behavioral choices that an individual made were influenced by the strengths of one's own efficacy beliefs.

6. Self-efficacy beliefs were future-oriented conclusions about the individual's capabilities to act in specific situations or contexts.

Social Cognitive Theory provided the conceptual foundation of reciprocal determination as a way to predict an individual's behavior (Pajares, 1997). Behaviors were the result of the ongoing relationship between external, internal forces and of the individual's past and present behaviors. This process, called triadic reciprocal causation (Bandura, 2001), involved the interplay of three elements: (a) environmental influences, (b) a person's own behavior, and (c) internal personal factors - cognitive, affective, and biological processes. Figure 1 shows this relationship. 


\section{BEHAVIOR}

\section{Human Development}

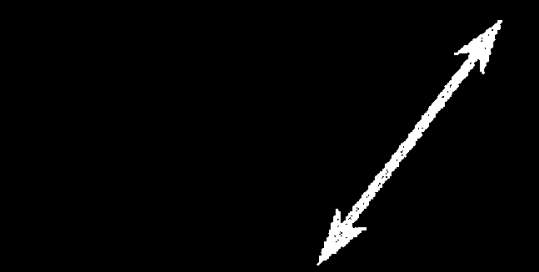

PERSONAL FACTORS

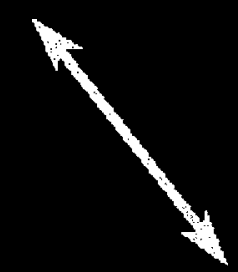

\section{Cognitive, Affective \\ (including beliers), \\ and Biological \\ Events}

Figure 1. Triadic reciprocal causation. From "Self-efficacy Beliefs in Academic Settings," by F. Pajares, 1996, Review of Educational Research, 66(4), pp. 543-578.

\section{Behavior Theory Detractors to Social Cognitive Theory}

"The debate over the importance of cognitive constructs in explaining individual behavior has existed for many years" (Earley \& Randel, 1995, p. 221). Dougher (1995) pointed to issues concerning the scientific framework of research in the field of efficacy. Bandura and most other mainstream psychologists were working within a mechanical framework, whereas Lee, Hawkins, and most behavioral analysts worked within a relational or contextual framework. These two frameworks entailed significantly different scientific objectives, units of analysis, views of causation, and requirements of an explanation.

From a behavioral perspective, Hawkins (1995) noted that causal implications of efficacy theory might be explained through other sources, such as hypnosis or . consistency theories, and that Bandura's model is a "derivative of Rotter's social learning 
theory" (p. 238). Lee and Smith (1996) indicated that long-term predictors of behaviors might be identified through various factors other than efficacy. Factors such as cultural differences may affect causation (Early \& Randel, 1995). "While the number of theories incorporating cognitive constructs has exploded since the 1950s, skeptics reassert the traditional viewpoint espoused in behaviorism" (Early \& Randel, 1995, p. 221).

\section{Sources of Efficacy Development}

Bandura (1997) argued that "perceived self-efficacy results from diverse sources of information conveyed vicariously and through social evaluation, as well as through direct experience" (p. 411). He identified four information sources for efficacy building: social persuasion, vicarious experiences, physiological/emotional arousal, and mastery experiences. A person uses information from each of these sources to develop efficacy beliefs through self-referent thought processes. This section provides definitions of these sources and examples related to education.

\section{Social Persuasion}

Social persuasion involved the development of beliefs based on the messages an individual receives from the persons around oneself (Bandura, 2001). Verbal judgments of others may build or reduce confidence, and may provide encouragement or negative feedback. These sources of persuasion may affect a person's decision to act. Although verbal persuasion was considered a weak source of information (Pajares, 1996), teachers might be influenced by verbal persuasion through administrative expectations, thoughts, and reactions from other teachers, parents, and students. Goddard, Hoy, et al. (2004) noted, "Social persuasion is another means of strengthening a faculty's conviction that 
they have the capabilities to set and achieve goals. Talks, workshops, professional development opportunities, and feedback about achievement can inspire action" (p. 8).

\section{Vicarious Experiences}

Vicarious experiences included the effects that were formed based on the actions of others (Bandura, 2001). These information sources might have greater impact on persons with less exposure or experience in a given task area (Schunk, 1983). The impact of role models was particularly important in efficacy beliefs that were developed through this source. Teachers might experience the effects of vicarious experiences through school-based peer-coaching, teacher-mentoring, and other teacher model processes (Bandura, 1997).

\section{Physiological Experiences}

Physiological/emotional arousal contributed to the development of efficacious beliefs, and in a recursive process beliefs also affect physiological states. In schools, pressures such as high-stakes testing might produce particular arousal states including excitement, relief, anxiety, stress, or fatigue (Bandura, 2001).

\section{Mastery Experiences}

Mastery experiences provided direct feedback to the individual about one's own capabilities to perform a given task (Bandura, 2001). A task outcome that a person perceived to be successful then raised the individual's efficacy beliefs. Likewise, a perceived negative task outcome decreased efficacy. As a person gained these experiences, a recursive developmental process of efficacy-building occurred. Revised perceptions more likely contributed to the expectations that future performances on 
similar tasks would also be either successful or have a negative outcome (Marks, 1999). Teachers may perceive that successful implementation of an instructional process warranted further use of that process. Social-cognitive theorists argued that mastery experience was the most powerful efficacy source (Knobloch \& Whittington, 2003). Genuine accomplishments of respectful tasks coupled with elaborated feedback were highly influential sources of efficacy information. Goddard, LoGerfo, et al. (2004) indicated that collective-efficacy was positively influenced by past mastery experiences and contributed to high-school achievement despite student socioeconomic status.

The key to integration of any of the four information sources was the individual's interpretation of the experience. "Changes in perceived efficacy result from cognitive processing of the diagnostic information that performances convey about capability rather than the performance per se". (Bandura, 1997, p. 81). The weight that was assigned to any particular source experience determined its applicability.

\section{Forms of Human-Agency}

Social Cognitive Theory identified three types of influential human-agency: personal-agency, proxy-agency, and collective-agency (Bandura, 1997). Each type of agency carried important implications for motivation, behavior, and impact of outcomes

in education in other arenas. Pajares (1996) emphasized the importance of the contextual definitions for agency and efficacy terminology in efficacy research. In this theoretical framework, agency was based on perceptions toward specific task outcomes rather than on general perceptions of ability. 


\section{Personal-Agency}

This form of agency was the basis for research in the area of teacher-efficacy. Personal-agency involved an individual's perspective on his/her ability to influence actions and outcomes (Bandura, 1997). The initial research on human-agency and efficacy was centered on personal-agency (Pintrich \& De Groot, 1990). An in-depth discussion of personal-agency is incorporated in the discussion of teacher-efficacy.

\section{Proxy-Agency}

Proxy-agency was explored based on institutionally and socially pragmatic contexts (Shields \& Brawley, 2006). Many situations were outside the scope of perceived personal control. In these instances, persons sought group members who had

access to desired outcomes. Persons relied on proxy-agency to fulfill needs and intended outcomes that could not be accomplished at the individual level. Perceived need to assign proxy-agency has been based on position, difficulty of tasks, resource access, intensity, and levels of associated responsibility and risks (Bandura, 2001).

\section{Collective-Agency}

Bandura identified collective-agency as "people's shared beliefs about their collective power to produce desired results" (Bandura, 2001, p. 6). Many outcomes required collaboration and coordination of knowledge, skills, and services. A person's perceptions about group influence on planning, motivation, and outcomes were essential components of collective-efficacy (Hoy, Sweetland, \& Smith, 2002). A comprehensive discussion of collective-agency is integrated into the discussion of collective teacherefficacy. 


\section{Social Cognitive Model of Self-Regulation}

Zimmerman's model of self-regulatory processes had important implications in efficacy research. This model was based on the constructs of Social Cognitive Theory. Self-regulatory skills developed through the recursive process of forethought, performance, and self-reflection (Zimmerman, Bandura, \& Martinez-Pons, 1992). Selfefficacy beliefs affected the development of the regulatory processes. In efforts to develop proactive strategies that supported changes in behaviors through changes in efficacy perceptions, this model provided important constructs for further research and application (Zimmerman, 2000). In educational research, there was growing interest in the relationships between self-efficacy, academic motivation, and self-regulation (Pintrich \& Schunk, 1996).

\section{Impact of Efficacious Beliefs}

The research literature supported assumptions that efficacy was a powerful predictor of behavior. Perceived self-efficacy was shown to correlate to specific behaviors in several domains including: affect, motivation, and cognition (TschannenMoran, Woolfolk Hoy, \& Hoy, 1998).

A primary research area centered on level of affective arousal and the association between efficacy beliefs and the degree of stress and depression one experiences (Bandura, 1989b). A person's perceived ability to cope with a challenging situation and perceived ability to control apprehensive feelings had clinical implications (Malpass, O'Neil, \& Hocevar, 1996; Pederson, Strickland, \& DesLauriers, 1991).

A person's efficacious beliefs could impact one's health (Bandura, 2004, 2005) in preventive care and coping with illness and was linked to specific health conditions 
including the ability to cope with pain from arthritis (Brekke, Hjortdahl, \& Kvien, 2001). Strength of efficacious beliefs was linked to recovery rates from traumatic events (Benight \& Bandura, 2004). Efficacy was correlated with vulnerability for depression in females (Bandura, Caprara, Barbaranelli, Gerbino, \& Pastorelli, 2003). Post-treatment self-efficacy perceptions were linked as a strong predictor for short-term maintenance of smoking cession (Coelho, 1984; Haaga \& Stewart, 1992; Pederson et al., 19.91). Binging and obesity in women (Cargill, Clark, Pera, Niaura, \& Abrams, 1999) was shown to have a strong relationship to efficacy.

It was partly on the basis of efficacy self-beliefs that people chose what challenges to undertake, how much effort to expend in the endeavor, and how long to persevere in the face of difficulties (Bandura, 1989b). Motivational links between efficacy and social modeling (Bandura, 2003; Schunk, 1983) and goal-setting (Zimmerman et al., 1992) were evidenced.

Efficacy connections to academic motivation and self-regulation were well documented in the research. Efficacy was shown to have a direct bearing on career choices and gender differences in career choices (Betz \& Hackett, 1981, 1983, 1986). Task persistence during math problem-solving (Chemers, Hu, \& Garcia, 2001), seatwork task-performance quality, and use of self-regulatory strategies (Pintrich \& De Groot, 1990) were related to efficacious beliefs.

Student achievement across disciplines was linked to efficacy. Pajares (2003, p. 140 ) indicated, "Writing self-efficacy makes an independent contribution to the prediction of writing outcomes and plays the mediational role that social cognitive theorists hypothesize" as evidenced through confirmatory research (Meier, McCarthy, \& 
Schmeck, 1984; Pajares, Miller, \& Johnson, 1999; Zimmerman \& Bandura, 1994). Math achievement (Malpass et al., 1996) and reading achievement (Tracz \& Gibson, 1986) were influenced by teacher efficacy. Students transitioned more successfully from middle to high school when teacher-efficacy was' high at the receiving school (Midgley, Feldlaufer, \& Eccles, 1989).

\section{Social Cognitive Career Theory}

Social Cognitive Career Theory (SCCT) was an extension of Social Cognitive Theory used to explore academic pursuits and career decision-making. The earliest precursor to the development of SCCT was credited to Hackett and Betz (1981) in their seminal study of women's career choices. Their study stimulated a body of research linking self-efficacy and career behavior (Cannon, 2004).

Lent, Brown, and Hackett (1994) used SCCT to examine the ways in which selfefficacy was impacted by socio-cultural factors commonly associated with diverse and disadvantaged populations. The four sources of efficacy identified in Social Cognitive Theory (social persuasion, vicarious experiences, physiological/emotional arousal, and mastery experiences) were viewed in light of the environmental and contextual factors that affect academic and vocational decisions. Factors that affect these decisions included (a) educational and career interests, (b) available choices, and (c) task persistence and performance (Lent et al., 1994).

SCCT was used to determine factors underlying career choices of various populations. Self-efficacy may have had a greater impact on vocational choices in situations where oppression and limited career choices existed (Lent et al., 1994). 
Gender and Social Cognitive Career Theory

Gender was a noted socio-cultural factor in research on the relationship between efficacy and career orientation. Women had lower self-efficacy for traditional male jobs (Betz \& Hackett, 1981). Gwilliam and Betz (2001) determined similar gender differences, but no racial differences, when measuring the relationship of efficacy and orientation toward math and science fields through three separate instruments. Lapan, Shaughnessy, and Boggs (1996) found that women had lower math self-efficacy, resulting in fewer females entering into math and science fields and in selection of college majors in related areas. Conversely, Hackett and Betz (1989) found that women did not have significantly lower math self-efficacy than men, but efficacy levels of both genders were a stronger predictor of math career orientation than math performance or prior achievement. In a study of eighth-graders, Ji, Lapan, and Tate (2004) found that students had higher self-efficacy for possible career paths that were more traditionally selected by their gender. Mau (2003) found that math self-efficacy and achievement levels in eighth-grade males were the two highest predictors of students' interests in pursuing science and math careers.

\section{Student Populations and Social Cognitive Career Theory}

Career decision self-efficacy was noted as a key predictor of vocational expectations of students in various minority and disadvantaged groups. Luzzo and McWhirter (2001) noted that ethnic minority students in the United States demonstrated more perceived educational barriers and lower self-efficacy for coping with perceived career-related barriers than their European-American counterparts. Additionally, Gushue and Whitson (2006) indicated no relation between efficacy and ethnic identity. In a 
study of urban African-American high-school students, stronger career decision-making self-efficacy was related to broader career path choices and greater engagement with career exploration processes (Gushue, Scanlan, Pantzer, \& Clarke, 2006). Teacher support was positively related to career decision self-efficacy and career outcome expectations for ninth-grade African-American students (Gushue et al., 2006).

Students with disabilities had lower self-efficacy and lower career exploration decisions than their nondisabled peers (Ochs \& Roessler, 2004). For students of low socioeconomic status, vocational/educational self-efficacy beliefs significantly predicted their vocational outcome expectations (Ali, McWhirter, \& Chronister, 2005; Ali \& Saunders, 2006).

\section{Teacher-Efficacy}

Teacher-efficacy research was founded in Social Cognitive Theory and was intertwined historically with the model development (Pajares, 1996). Weber and Omotani (1994) noted that teachers' self-efficacy ratings were predictive of student achievement. Teachers who had stronger efficacy beliefs developed more challenging instructional activities and instructional goals for their students than did teachers with lower efficacy beliefs (Brophy, 1986; Burton, 1995; Pajares, 1996; Ross, 1994). Teachers with stronger efficacy levels helped students to achieve their end-of-year goals more regularly than teachers with lower levels of efficacy (Allinder, 1995). Efficacy was linked to teachers' levels of professional commitment (Coladarci, 1992). Teacher-efficacy was influenced most during the first 10 weeks of the school year (Knobloch, 2002) when new teachers were eager and energized in their new positions. Deliberate fostering of efficacious 
beliefs supported the development of professional learning-community at the school-site level (Ross \& Gray, 2004).

\title{
Teacher-Efficacy Instrumentation
}

\author{
Instrumentation Issues
}

There have been many attempts to develop effective instruments to measure this construct. The definition and measures of teacher-efficacy have been an ongoing source of debate and research. Pajares (1996) stated,

Bandura has cautioned researchers attempting to predict academic outcomes from students' self-efficacy beliefs, that to increase accuracy of prediction, they would be well advised to follow theoretical guidelines regarding specificity of self-efficacy assessment and correspondence with critical tasks. This caution has often gone unheeded in educational research, and efficacy assessments have too often been global and general and have lacked the specificity of measurement, consistency with the critical task, and microanalytic analysis that optimizes the predictive power of self-efficacy beliefs. (p. 30)

Tschannen-Moran et al. (1998) indicated that this debate centers on two broad issues:

1. Whether teacher-efficacy should be measured specifically within the context of specific behaviors, as based on Bandura's definition, and

2. Whether construct validity of scores from primary instruments has been questioned.

\section{Constructs for Instrumentation Development}

Bandura (1997) stressed the importance of three domains for efficacy

measurement: level, generality, and strength. Level indicated the degree of efficacy beliefs based on the amount of perceived task difficulty. For example, a person's perceived efficacy to complete easy Sudoku puzzles may be higher than his or her perceived efficacy to complete hard Sudoku puzzles. Generality reflected the degree of 
transferability of efficacy beliefs between tasks or activities (such as between completing Sudoku puzzles and crossword puzzles). Measurements of strength indicated the intensity of self-efficacy beliefs around one's certainty to perform a given task or activity (Pintrich \& De Groot, 1990).

Measurements were further defined and analyzed based on key characteristics that reflect the theoretical base of Social Cognitive Theory (Tschannen-Moran et al., 1998):

1. Efficacy tests focused on capabilities for specific outcomes rather than for general outcomes.

2. Tests were based on mastery criteria rather than normative criteria in that a person's efficacy beliefs are judged against oneself rather than against others.

3. Tests assessed beliefs that are futures oriented.

4. Tests were sensitive to the environmental conditions of a given task.

\section{Historical Review of Instruments}

A review of the historical development of teacher-efficacy measurements provided a rationale for analysis and purposeful selection of instrumentation for this research study (Pajares, 1997). Key instruments that represented the evolution of this process are addressed. Bandura's conception of efficacy-measurement constructs served as a foundation for analysis of efficacy instrumentation.

\section{RAND Scale}

In 1976, Amour's enhancement of a RAND Research scale was commonly viewed as the precursor to all teacher-efficacy instrumentation. The influence of the RAND scale continued to impact the development of instruments and the ongoing debate 
over efficacy research constructs. This early scale measured teachers' perceptions of their control over student motivation and learning. Founded on Locus of Control Theory (Rotter, 1966), student learning and motivation were assumed reinforcers of teaching behaviors. The two relevant items of this questionnaire included the following ideas:

1. When it comes right down to it, a teacher really can't do much because a student's motivation and performance depends on his or her home environment.

2. If a teacher tries really hard, he/she can get through to even the most difficult or unmotivated students.

\section{Teacher-Efficacy Scale}

Gibson and Dembo (1984) challenged the two-item RAND scale on both construct definition and reliability. They relabeled the two RAND items to correspond with constructs of Social Cognitive Theory: RAND Item 1 measured general teaching efficacy (GTE) or a teacher's belief of whether teaching can influence student learning regardless of other instructional factors outside the scope of teacher control; RAND Item 2 measured personal teaching efficacy (PTE) or a teacher's perceived ability to have a positive impact on student learning.

Based on this work, Gibson and Dembo developed the Teacher-Efficacy Scale (TES). They further refined the RAND instrument by adding 16 additional items ( 9 additional items for PTE, and 7 additional items for GTE). This advancement opened opportunities for extensive research that established correlations between teacher-efficacy and educational outcomes (Pajares, 1997).

The Teacher-Efficacy Scale contributed to the development of additional instruments that accounted for the need to ensure contextual specificity. For example, the 
Science Teaching Efficacy Belief Instrument (Riggs \& Enochs, 1990) specified the personal and outcome expectancy items from the TES for science teachers. Emmer and Hickman (1991) used the TES to correlate efficacy to classroom management. Although the Teacher-Efficacy Scale showed weaknesses in discriminant validity of PTE and GTE scores (Colardarci \& Fink, 1995) and weaknesses in factor analysis (Guskey \& Passaro, 1994), the instrument initiated research on multiple dimensions of efficacy. TschannenMoran et al. (1998) indicated that

a valid measure of teacher efficacy must assess both personal competence and an analysis of the task in terms of the resources and constraints in particular teaching contexts. Most existing measures of teacher efficacy do not include both dimensions of efficacy. (p. 27)

\section{Collective-Efficacy Constructs}

The concept of efficacy extended to a collective perspective. Bandura (1997) noted, "Personal-agency operates within a broad network of sociostructural influences" (p. 6) and the "theory extends the analysis of the mechanisms of human-agency to the exercise of collective-agency" (p. 7).

The four sources of efficacy identified in Social Cognitive Theory also applied in the collective domain. Goddard, Hoy, et al. (2004) noted, "Social persuasion is another means of strengthening a faculty's conviction that they have the capabilities to set and achieve goals. Talks, workshops, professional development opportunities, and feedback about achievement can inspire action" (p. 8). Vicarious experiences might have included visits to other teachers' classes, peer-coaching, or site visits and collaborative professional dialogs at model schools. Physiological/emotional feedback may have arisen from the collective expectations of teachers in departments or within schools as 
data are collected for high-stakes tests. Mastery experiences that were celebrated and shared could support higher levels of collective-efficacy perception (Mawhinney et al., 2005).

Collective-efficacy represented the beliefs of group members concerning "the performance capability of a social system as a whole" (Bandura, 1997, p. 469). In the context of school settings, collective-efficacy referred to teacher perceptions that the faculty, as a group, could plan and implement procedures that will positively impact their students (Goddard, Hoy, et al., 2004).

Although teachers commonly worked in isolated classrooms for large portions of each work day, Bandura (1997) noted,

People working independently within a group structure do not function as social isolates totally immune to the influence of those around them. . . . The resources, impediments, and opportunities provided by a given system partly determine how efficacious individuals can be, even though their work may be only loosely coupled. (p. 469)

\section{Relationship of Collective-Efficacy and Education}

In high-efficacy schools, teachers established challenging instructional benchmarks, instruction to support mastery learning, and believed that their students could reach high academic goals (Bandura, 1997). Students demonstrated higher achievement when their teachers had higher efficacy (Cybulski, 2003; Goddard, 2002; Grass, 2004; Larrick, 2004). Weak collective-efficacy resulted in weaker student gains. Students decreased their own expectations of their math performance after moves from elementary to junior high schools when they moved from high efficacy to lower efficacy teachers (Midgley et al., 1989). High levels of perceived collective-efficacy were associated with high student achievement in high poverty schools (Grass, 2004). 
Teacher-efficacy was important because teachers' collective beliefs about their instructional responsibilities impacted the amount of student learning that occurred in their classrooms (Lee \& Smith, 1996). Math and reading achievement increased in relation to the degree of collective-efficacy of teachers in low socioeconomic schools (Larrick, 2004). Independent of socioeconomic status, significant positive relationships were evidenced between collective-efficacy and student achievement on state writingassessments of Grade 8 students (Tschannen-Moran \& Barr, 2004). Reading and math achievement increased in elementary schools despite socioeconomic level of students (Cybulski, 2003; Cybulski, Hoy, \& Sweetland, 2005; Goddard, Sweetland, \& Hoy, 2000).

School culture and climate (Mackenzie, 2000; Marin, 2001) were influenced by collective-efficacy. Teacher feelings of trust toward each other related to collectiveefficacy (Adams, 2003; Charvez, 2004; Dale, 2004). Mastery experiences during the professional development on reading strategies increased teachers' sense of collective efficacy (Oxendine, 2005).

School personnel in leadership roles were shown to contribute to the collectiveefficacy beliefs of a school (Glenn, 2003). Collective-efficacy related to supportive principal behaviors of instructional modeling, support to individual teachers, and focus on school mission (Armstong-Coppins, 2003; LeRoy, 2005; Tagger, 2002) and contributed to organizational commitment in mentoring relationships (Allen, 2003).

\section{Relationship of Collective-Efficacy and Change Processes}

Olivier (2001) identified collective-efficacy as the strongest predictor of schoolorganizational effectiveness. As schools worked to improve student outcomes through 
teacher use of instructional innovations, information on the efficacious beliefs of the staff needed to be collected, examined, and analyzed to affect needed change. "Just as individual teacher-efficacy partially explains the effect of teachers on student achievement, from an organizational perspective, collective-efficacy helps to explain the differential effect that school cultures have on teachers and students" (Goddard, Hoy, et al., 2004, p. 4).

Hall and Hord (2006) indicated, "Even when the change is mandated, some individuals will delay implementation" (p. 7). They indicated that significant procedural differences exist between developing and implementing an innovation. Collectiveefficacy beliefs of teachers impacted professional-learning environments and meaningful change efforts (Dellinger, 2001). Strong collective-efficacy of a group of teachers could interfere with reform processes (Collins, 2001). Therefore, it was critical that schools be responsive to the needs of teachers in this change process.

Collective-efficacy was important to teacher use of new innovations because it predicted the level of group effort and group performance (Lin, 2001). Furthermore, collective-efficacy impacted group goal development and goal commitment (Ross \& Gray, 2004). Teachers with higher levels of collective-efficacy showed increased professional behaviors (Scott, 2003) and more effective decision-making skills (Tasa, 2002).

Hall and Hord (2006) indicated that mandated change could work, but organizational change could not occur until individuals within the organization changed. Individual teacher-implementation of research-based instructional practices was critical to student achievement, yet teachers were often perceived to be resistant to school 
improvement efforts. "Many educators feel that it is not the quality of the innovation that is lacking; rather, this failure is due to our lack of knowledge about and attention to the process of change and the requirements for successful change" (Loucks, Newlove, \& Hall, 1998, p. 1). School culture and norms might limit teachers' beliefs about their capacity to learn and perform at high levels (Johnson \& Donaldson, 2007) and thus impact negatively on student achievement. It is important that levels of collectiveefficacy could be altered to improve the professional learning-community of a school (Garcia, 2004).

\section{Collective-Efficacy Instrumentation}

The two primary approaches were recognized in the examination of organizational collective-efficacy. Bandura (1997) indicated that the selection of either instrumentation type largely depended on the nature of the organization that is being examined. The selection of methods depended on the load assigned to individual or interdependent factors of the organization.

If the organizational connections between individuals were intermittent or marginal, Bandura refered to this relationship structure as "loose coupling." In such cases, the aggregation of individuals' measures might provide the appropriate means to measure collective-efficacy. In organizations where interdependent group relationships between individuals were required, a tighter coupling approach may be warranted. In this type of instrumentation, "we" statements, rather than "I" statements, were used. Bandura (2000) indicated, "The relative predictiveness of the two indices of collective efficacy will largely depend on the degree of interdependent effort needed to achieve desired results" (p. 77) 


\section{Summary}

This chapter provided a summation of the theoretical base for Social Cognitive Theory that underscored the importance of collective-efficacy research in schools.

Despite the ongoing debates over construct definitions for self-concepts such as efficacy, esteem, and confidence, research in this field was critical to the change process that was needed to increase student achievement. Bandura (2001) noted, "High efficacy schools accept responsibility for their students' outcomes. Teachers in schools with high collective-efficacy do not accept low student achievement as an inevitable byproduct of low socioeconomic status, lack of ability, or family background" (p. 5).

Continued research involving the connections between teachers' sense of collective-efficacy and student achievement was essential (Smith, Hoy, \& Sweetland, 2002). Connections between collective-efficacy and other factors that may have direct and indirect impacts on achievement, such as conditions with vocational-technical school settings, were equally important to identify.

Malloch (1999) indicated,

There is a need for quality research into vocational education and training which will assist in creating more organizations and workplaces where recognition of complexity, visionary leadership, excellent management behaviour, the presence of a learning culture, the nature of the organization, and appropriate reward systems operate on a daily basis. (p. 7) 


\section{CHAPTER 3}

\section{METHODOLOGY}

\section{Introduction}

The purpose of this study was to determine the relationship between collectiveefficacy beliefs and student achievement in vocational-technical high-school settings. This chapter describes and justifies the research design and research approach of the study. Variables are defined. Characteristics of the sample, sampling methods, and sampling size are addressed. The instrumentation type, instrument description and assessment, administration, scoring procedures, and location of raw data are included. This chapter also includes an initial discussion of the descriptive analysis of the data. A discussion of how participants' rights were protected is also addressed.

\section{Identification of Variables}

This study investigated the relationship between two variables: collective-efficacy and student achievement. Collective-efficacy was measured at the school level. Student achievement was collected in the areas of mathematics, reading, science, and interdisciplinary writing at the school level. 


\section{Participants}

Population and Sample for the Independent Variable

The purpose of this study was to measure the effects of collective-efficacy from a teacher perspective. Therefore, teachers from 17 vocational-technical high schools were selected to participate in this study. Data were obtained from teachers across all academic and trade departments, resulting in a sample of 730 participants.

\section{Population and Sample for the Dependent Variables}

To determine student achievement, the aggregated scores of Grade 10 students were calculated for those Grade 10 students who took the standard version of the Connecticut Academic Performance Test. Student scores were obtained in all schools from which the independent variable sample is derived. Ninety-nine percent of Grade 10 students participated in the study.

\section{Sample Selection}

To determine the level at which the results were biased due to student-, teacher-, or school-based factors, skewness and kurtosis measures were undertaken. Furthermore, achievement comparisons between the 5 Title 1 schools and 12 non-Title 1 schools were examined through analysis of variance for reading, writing, mathematics, and science.

Title 1 schools were identified through parameters set by Title 1 Section 101: Improving the Academic Achievement of the Disadvantaged (No Child Left Behind Act, 2001). Under this act, school districts target the Title 1 funds to their schools with the highest percentages of children from low-income families. The five schools in this district that 
qualified for Title 1 funds met the requirement that at least $40 \%$ of the enrolled students were from low income families.

Additionally, it is important to note that the samples were uniform in several areas. The following list indicates universal characteristics evidenced across all 17 schools in the district that contributed to strong variable controls:

1. Every teacher in the district was required to use a universal lesson plan format that includes critical teaching behaviors of advance organizers, schema activators, postorganizers, flexible grouping strategies, explicit instruction, and student-outcome-based objectives and assessments (see Appendix A).

2. Every teacher received professional development in the form of coaching and workshops in the areas of instruction, behavior management, and school climate.

3. All academic and trade courses were taught based on an explicit curriculum that is used across schools to ensure integrity of content acquisition. All schools offered the same academic courses and trade clusters (see Appendix B).

4. All teachers received universal resources for teaching and professional growth.

5. All teachers were certified in their assigned subject areas (see Appendix C).

6. All students were accepted into the school district based on universal criteria that includes academic achievement, behavior, and school attendance (see Appendix D).

7. All students received free transportation to the schools.

8. All schools had the same graduation policies and requirements (see Appendix E). 
9. All students had access to the schools from at least three surrounding towns or cities. None of the schools drew only from local education agencies that qualified for Title 1 funds.

\section{Instrumentation}

This study used two instruments for data collection. The independent variable of collective-efficacy was measured through use of the Collective Teacher-Efficacy Belief Scale (CTEBS). The dependent variable was measured on the Connecticut Academic Performance Test (CAPT). A comprehensive description of the concepts each test measured, how scores were calculated and interpreted, reliability and validity, and administration processes are included in this section.

\section{Collective Teacher-Efficacy Belief Scale (CTEBS)}

\section{Instrument Selection}

The Collective Teacher-Efficacy Belief Scale (CTEBS) measured collectiveefficacy at a group level. This scale was an adaptation of the Teacher Sense of Efficacy Scale (TSES) developed by Tschannen-Moran and Woolfolk Hoy (2001). Given the interdependent nature of instructional tasks, the group orientation of this instrument was appropriate. Additionally, this instrument was designed for specific application in teacher-efficacy research, thus making it appropriate for use in this study.

\section{Instrument Description}

The CTEBS provided a questionnaire format. It included 12 items and contains two subsets of collective-efficacy: instructional strategies and group discipline. Teachers 
rate themselves on a 9-point Likert-like scale for each item. Appendix F provides a sample of this questionnaire.

\section{Instrument Administration}

For this study, the Collective Teacher-Efficacy Belief Scale was administered electronically. Participants accessed the instrument through the school district website. Written instructions for test completion were available at the top of the questionnaire. Participants completed the test through computer access in their classrooms. Raw data were compiled on the website and accessed through the secure central office administrative system.

\section{Instrumentation Characteristics}

Test developers Tschannen-Moran and Barr (2004) indicated, In factor analysis, the 12 items loaded on one factor, with factor loadings that ranged from .79 to .58 . When the two factors were specified, the rotated factors divided along the predicted content, with factor loadings on the 6 items in the instructional strategies subscale ranging from .78 to .67 and the 6 items in the student discipline subscale ranging from .78 to .64 . (p. 188)

This instrument showed instructional-strategy-subscale reliability of .94, studentdiscipline-subscale reliability of .96 , and the 12-item scale demonstrated reliability of .97 .

\section{Connecticut Academic Performance Test}

\section{Instrument Selection}

The Connecticut Academic Performance Test (CAPT) was used to determine student achievement. Section 10-14n of the Connecticut General Statutes requires all students in the public schools in Grade 10 to participate in this state assessment. The 
selection of this measure to collect data on the independent variable was based on its use in accountability processes in statewide education.

\section{Instrument Description}

The CAPT measured student achievement in four content areas: Mathematics, Science, Reading Across the Disciplines (based on a Response to Literature test and a Reading for Information test), and Writing Across the Disciplines (based on two Interdisciplinary Writing tests and an Editing \& Revising test). The CAPT assessed student knowledge and skills in each content area based on the Connecticut curriculum frameworks. Appendix G provides the rationale for CAPT administration.

Student results were reported in five performance categories: Advanced, Goal, Proficient, Basic, and Below Basic for each academic area. Appendix H provides specifications for proficiency levels in each CAPT test area.

\section{Instrument Administration}

The CAPT was administered through a rigorously controlled process. The specific testing dates, length of testing sessions, and administration procedures were set at the state level and were uniform across districts.

Students independently completed each test component through prescribed procedures specific to each given test. Each test was administered in a regular classroom setting, and a test monitor assured administration integrity. The four tests were administered on separate test dates and were completed within prescribed time allotments. Appendix I provides specific CAPT administration information. 


\section{Instrumentation Characteristics}

As described in the CAPT information site of the Connecticut State Department of Education website, scale scores ranging from 100 to 400 were generated for each of the content areas: Mathematics, Science, Reading Across the Disciplines, and Writing Across the Disciplines. The scale-scores were associated with a performance level (i.e., below-goal, goal, advanced, proficient).

\section{Null Hypotheses}

For statistical analysis purposes, I created four null hypotheses generated from my research questions. The following hypotheses were established for my study:

\section{Null Hypothesis 1}

Academic performance on the Mathematics Component of the Connecticut Academic Performance Test (CAPT) cannot be predicted by a vector of scores consisting of Collective Efficacy Instructional Subscale, the Collective Efficacy Discipline subscale, or the Total Score on Collective Efficacy.

\section{Null Hypothesis 2}

Academic performance on the Science Component of the Connecticut Academic Performance Test (CAPT) cannot be predicted by a vector of scores consisting of Collective Efficacy Instructional Subscale, the Collective Efficacy Discipline subscale, or the Total Score on Collective Efficacy. 


\section{Null Hypothesis 3}

Academic performance on the Reading for Information Test of the Connecticut Academic Performance Test (CAPT) cannot be predicted by a vector of scores consisting of Collective Efficacy Instructional Subscale, the Collective Efficacy Discipline subscale, or the Total Score on Collective Efficacy.

\section{Null Hypothesis 4}

Academic performance on the Writing Across the Disciplines Component of the Connecticut Academic Performance Test (CAPT) cannot be predicted by a vector of scores consisting of Collective Efficacy Instructional Subscale, the Collective Efficacy Discipline subscale, or the Total Score on Collective Efficacy.

\section{Data Analysis}

This section provides an explanation of the research procedures reported in chapter 4. As preliminary statistical analyses, I executed descriptive statistics on all variables in the study. I calculated the mean scores and standard deviations on the dissertation variables and reported on each. Then I undertook the primary statistical analyses.

I conducted six separate analyses of variance to address possible issues of bias related to school profile differences. The criterion or dependent variables $(\mathrm{Y})$ were the four academic performance measures (Math, Writing, Science, and Reading) and the two factors of collective-efficacy (Instruction and Discipline) The predictor or independent variables $(\mathrm{X})$ included schools categorized as Title 1 and non-Title 1 status. 
I conducted four separate multiple regression analyses to address the four null hypotheses. The criterion or dependent variables $(\mathrm{Y})$ were each of the four academic performance measures (Math, Writing, Science, and Reading). The vector of predictor variables was the two subscales of the Collective Efficacy test and the Total Score. Specifically, these were the Instructional subscale (X1), the Discipline subscale (X2), and the Total Score (X3). All of the three were independent or predictor variables.

Given the a posteriori research process, I used statistical criteria to build a subset of predictors. I executed the four multiple regression procedures in a stepwise procedure where the predictor variable that explained the most variance in the dependent variable emerged first, and then subsequent variables were entered into the regression equation.

My use of regression as the method of analysis was based on key assumptions of linearity of relationships, fixed $\mathrm{X}$ variable, lack of measurement errors, and lack of specification errors (Pedhazur, 1982). I assumed linearity through the connection of variable relationships to Social Cognitive Theory and past research (as addressed in the literature review). The reliability measures established for the $\mathrm{X}$ and $\mathrm{Y}$ variable tests supported a lack of measurement errors. I viewed specification errors as minimal in that linear relationships assumed in this research model were supported through Social Cognitive Theory and included variables appropriate to tests of that theory. Normality was established through tests of skewness and kurtosis. Conversely, I assumed that some level of inter-collinearity would occur since the predictor variables were subsets of one test instrument, thus impacting the findings.

I conducted a factor analysis using the collective-efficacy data to respond to the inter-collinearity determined through the Pearson Product-Moment Correlations. The 
original factor analysis of the CTEBS was completed to validate the components and total test instrument by determining the clusters under which each variable was related. I executed this statistical procedure as a confirmatory measure to assure that each test item corresponded with the components established through the original test development. I completed the factor extraction through Principal Component Analysis. The KMO and Bartlett's test of sphericity determined normality of the sample and the adequacy of the variables for use in the factor analysis. I used the Varimax with Kaiser Normalization method to rotate the factors. Rotation of the factors converged in three rotations. In keeping with the assumptions of multiple linear hypothesis, the data were linear, interval, and contained relevant variables.

\section{Availability of Raw Data}

Raw data for each test administration are available upon request. Secondary data obtained through the school system were used in this study.

\section{Participant Rights Protection}

I applied for and received approval to conduct this study through the Andrews University Human Subjects Review Board. The data were collected by the district and were independent of the intended research of this study. The data for the dependent and independent variables were part of ongoing research to evaluate professional development at each school. Confidentiality was maintained in that actual school names associated with each school code did not disclose the teacher or student population and sample descriptions. 


\section{CHAPTER 4}

\section{RESULTS}

\section{Introduction}

The purpose of my study was to explore the relationship between collectiveefficacy beliefs of teachers and student achievement. I examined the collective-efficacy beliefs of academic and trade teachers in 17 Connecticut technical high schools and the relationship between those beliefs to student achievement on the Connecticut Academic Performance Test. My study sought to determine relationships between (a) teachers' overall perceptions of collective-efficacy and student achievement, (b) teachers' perceptions of their collective instructional efficacy to student achievement, and (c) teachers' perceptions of their collective discipline efficacy to student achievement. For each collective-efficacy domain, I explored the relationships to mathematics, science, reading, and writing achievement. In this chapter, I provide sample descriptions, collective-efficacy data, student achievement data, tests of the hypotheses, discussion of the findings, and a summary.

\section{Description of the Samples}

\section{Collective-Efficacy Sample}

I collected collective-efficacy data from teachers in all 17 high schools in the technical high-school district. Data were obtained from teachers across academic and 
trade departments. Seven hundred thirty teachers served as subjects in the study, and this number represented $71 \%$ of the total teaching staff. Table 1 reports the schools from which the teachers were drawn and the respective numbers of teachers from each school. Since the teachers completed the collective scale voluntarily and without a requirement for content-area disclosure, a specific ratio of trade and academic teacher participation could not be determined.

To determine collective-efficacy, I collected teachers' scores on the Collective Teacher-Efficacy Belief Scale (CTEBS). Rated on a 9-point Likert-like scale, the 12 items on the CTEBS produced two scale scores: Instructional Strategies (Instruction) and Group Discipline (Discipline).

\section{Student Achievement Sample}

I collected achievement scores for Grade 10 students across the 17 schools in the areas of mathematics, science, reading, and writing. For each of the four test areas, the number of participants across the schools ranged from 99.3 to $99.6 \%$ of the total population of 2,592 students. Students who did not take this test were exempt through No Child Left Behind parameters for English Language Learners and special education. Table 2 represents this information.

To determine student achievement, I accessed the scaled scores (100-400) on the Connecticut Academic Performance Test (CAPT). The CAPT measured student achievement in four content areas: Mathematics, Science, Reading Across the Disciplines (based on a Response to Literature test and a Reading for Information test), and Writing Across the Disciplines (based on two Interdisciplinary Writing tests and an Editing \& Revising test). 
Table 1

Number of Teachers by Participating School

\begin{tabular}{|c|c|c|c|}
\hline $\begin{array}{l}\text { Participating } \\
\text { schools } \\
\text { (coded) }\end{array}$ & $\begin{array}{l}\text { Number of teacher } \\
\text { subjects/total teachers } \\
\text { in the school }\end{array}$ & $\begin{array}{l}\text { Percentage of teacher } \\
\text { subjects from } \\
\text { the school }\end{array}$ & $\begin{array}{l}\text { Percentage of total } \\
\text { teacher sample } \\
\text { in the study }\end{array}$ \\
\hline 1 & $70 / 79$ & 89 & 10 \\
\hline 2 & $33 / 59$ & 56 & 4 \\
\hline 3 & $21 / 51$ & 41 & 3 \\
\hline 4 & $58 / 65$ & 89 & 8 \\
\hline 5 & $59 / 76$ & 78 & 8 \\
\hline 6 & $40 / 51$ & 78 & 6 \\
\hline 7 & $51 / 70$ & 73 & 7 \\
\hline 8 & $22 / 57$ & 39 & 2 \\
\hline 9 & $42 / 51$ & 82 & 6 \\
\hline 10 & $42 / 51$ & 82 & 6 \\
\hline 11 & $22 / 40$ & 55 & 3 \\
\hline 12 & $50 / 68$ & 74 & 7 \\
\hline 13 & $44 / 65$ & 68 & 6 \\
\hline 14 & $43 / 53$ & 81 & 6 \\
\hline 15 & $40 / 50$ & 80 & 5 \\
\hline 16 & $34 / 70$ & 49 & 5 \\
\hline 17 & $59 / 65$ & 91 & 8 \\
\hline Total & $730 / 1,021$ & 71 & 100 \\
\hline
\end{tabular}


Table 2

Number of Students by Participating School

\begin{tabular}{|c|c|c|c|c|c|}
\hline School & $\begin{array}{c}\text { Total student } \\
\text { population }\end{array}$ & Science & Math & Reading & Writing \\
\hline 1 & 238 & 238 & 237 & 237 & 238 \\
\hline 2 & 139 & 139 & 139 & 138 & 138 \\
\hline 3 & 163 & 162 & 161 & 162 & 163 \\
\hline 4 & 136 & 133 & 130 & 132 & 132 \\
\hline 5 & 144 & 141 & 141 & 140 & 140 \\
\hline 6 & 141 & 140 & 141 & 141 & 140 \\
\hline 7 & 164 & 164 & 164 & 164 & 163 \\
\hline 8 & 142 & 142 & 142 & 141 & 140 \\
\hline 9 & 136 & 134 & 133 & 135 & 133 \\
\hline 10 & 109 & 109 & 109 & 109 & 109 \\
\hline 11 & 65 & 65 & 63 & 63 & 63 \\
\hline 12 & 183 & 183 & 183 & 183 & 183 \\
\hline 13 & 190 & 189 & 188 & 189 & 189 \\
\hline 14 & 124 & 124 & 124 & 124 & 124 \\
\hline 15 & 142 & 142 & 142 & 142 & 142 \\
\hline 16 & 207 & 207 & 207 & 207 & 207 \\
\hline 17 & 169 & 169 & 169 & 169 & 169 \\
\hline Total & 2,592 & 2,581 & 2,573 & 2,576 & 2,573 \\
\hline Percentage & & 99.6 & 99.3 & 99.4 & 99.3 \\
\hline
\end{tabular}




\section{Hypotheses}

The following hypotheses were established for this study. Stated as null hypotheses, they were as follows:

\section{Null Hypothesis 1}

Academic performance on the Mathematics Component of the Connecticut Academic Performance Test (CAPT) cannot be predicted by a vector of scores consisting of Collective Efficacy Instructional Subscale, the Collective Efficacy Discipline subscale, or the Total Score on Collective Efficacy.

\section{Null Hypothesis 2}

Academic performance on the Science Component of the Connecticut Academic Performance Test (CAPT) cannot be predicted by a vector of scores consisting of Collective Efficacy Instructional Subscale, the Collective Efficacy Discipline subscale, or the Total Score on Collective Efficacy.

\section{Null Hypothesis 3}

Academic performance on the Reading for Information Test of the Connecticut Academic Performance Test (CAPT) cannot be predicted by a vector of scores consisting of Collective Efficacy Instructional Subscale, the Collective Efficacy Discipline subscale, or the Total Score on Collective Efficacy.

\section{Null Hypothesis 4}

Academic performance on the Writing Across the Disciplines Component of the Connecticut Academic Performance Test (CAPT) cannot be predicted by a vector of 
scores consisting of Collective Efficacy Instructional Subscale, the Collective Efficacy Discipline subscale, or the Total Score on Collective Efficacy.

\section{Preliminary Statistical Analysis}

I executed two preliminary statistical processes to prepare the data for multiple regression analysis. First, I collected descriptive statistics on the collective-efficacy and achievement variables. Second, I executed Pearson Product-Moment Correlations to determine the relationship between predictor variables (CTEBS Instruction, CTEBS Discipline, and CTEBS Total Score) and each of the respective criterion variables (CAPT Mathematics, Science, Reading and Writing). Finally, I conducted a confirmatory factor analysis of the CTEBS to explore and respond to the inter-collinearity illustrated through the second procedure.

\section{Collective-Efficacy Variables}

I collected descriptive statistics on the three independent variables of this research. As reported in Table 3, I included the means and standard deviations for the 12 items on the CTEBS, the CTEBS Instructional Strategies Subscale, the CTEBS Group Discipline Subscale, and the CTEBS Total score.

The results indicated a normal population as noted in Table 4. Skewness and kurtosis measures for the Instruction Scale Score, Discipline Scale Score, and Total Score indicated normality of the sample for each test domain as all scores fell between $+/-1$, and all standard error measures were low. 
Table 3

Descriptive Statistics on Collective-Efficacy Variables

\begin{tabular}{llc}
\hline CTEBS variables & Mean & $\begin{array}{c}\text { Standard } \\
\text { deviation }\end{array}$ \\
\hline Item 1 instruction & 7.87 & 1.2 \\
Item 2 instruction & 7.59 & 1.3 \\
Item 3 discipline & 7.85 & 1.3 \\
Item 4 discipline & 7.60 & 1.5 \\
Item 5 instruction & 7.34 & 1.3 \\
Item 6 instruction & 7.41 & 1.4 \\
Item 7 discipline & 6.58 & 1.7 \\
Item 8 discipline & 6.83 & 1.7 \\
Item 9 instruction & 7.37 & 1.3 \\
Item 10 discipline & 6.84 & 1.6 \\
Item 11 instruction & 7.24 & 1.5 \\
Item 12 discipline & 7.77 & 1.3 \\
\hline Instruction subscale & 88.30 & 6.5 \\
Discipline subscale & 4.83 & 12.6 \\
Total score & 43.47 & \\
\hline & & \\
\hline
\end{tabular}


Table 4

Collective-Efficacy Sample Normality Descriptors

\begin{tabular}{lccc}
\hline Descriptor & $\begin{array}{l}\text { Instruction } \\
\text { scale score }\end{array}$ & $\begin{array}{c}\text { Discipline } \\
\text { scale score }\end{array}$ & $\begin{array}{l}\text { Total } \\
\text { score }\end{array}$ \\
\hline Skewness & -.670 & -.741 & -.678 \\
Std. error of skewness & .090 & .090 & .090 \\
Kurtosis & .493 & .564 & .558 \\
Std. error of kurtosis & .181 & .181 & .181 \\
\hline
\end{tabular}

To further isolate the boundaries of my results, I conducted two analysis of variance tests (ANOVAs) to determine the impact of socioeconomic status of schools on teacher perceptions of collective-efficacy. I compared collective teacher-efficacy at Title 1 and non-Title 1 schools in instruction and discipline. Tables 5 and 6 indicate the results of my findings.

The results indicated no significant difference in mean scores between Title 1 and non-Title 1 schools, as noted in Table 5. The $F$ ratio of 4.318 provided a $p$ value significance of .055 at the alpha level of .05 , which indicated that the score fell just outside the range of significant influence. These results indicated that Title 1 school identification on the collective efficacy perceptions of student achievement is not significant.

The results indicated a significant difference in mean scores between Title 1 and non-Title 1 schools, as noted in Table 6 . The $F$ ratio of 10.832 provided a $p$ value significance of .005 at the alpha level of .05 and indicated a significant influence of Title 1 school identification on the collective-efficacy perceptions around student discipline. 
Table 5

ANOVA Title 1 Relationship to Collective-Efficacy Beliefs on Instruction

\begin{tabular}{|c|c|c|c|c|c|c|c|}
\hline & & & $S S$ & $d f$ & $M S$ & $F$ & Sig. \\
\hline $\begin{array}{l}\text { Instruction } \\
\text { Title } 1\end{array}$ & $\begin{array}{l}\text { Between } \\
\text { groups } \\
\text { Within } \\
\text { groups } \\
\text { Total }\end{array}$ & Combined & $\begin{array}{r}9.896 \\
34.376 \\
44.273\end{array}$ & $\begin{array}{l}15 \\
16\end{array}$ & $\begin{array}{l}9.896 \\
2.292\end{array}$ & 4.318 & $.055^{*}$ \\
\hline
\end{tabular}

Table 6

ANOVA Title 1 Relationship to Collective-Efficacy Beliefs on Discipline

\begin{tabular}{|c|c|c|c|c|c|c|c|}
\hline & & & $S S$ & $d f$ & $M S$ & $F$ & Sig. \\
\hline $\begin{array}{l}\text { Instruction } \\
\text { Title } 1\end{array}$ & $\begin{array}{l}\text { Between } \\
\text { groups } \\
\text { Within } \\
\text { groups } \\
\text { Total }\end{array}$ & Combined & $\begin{array}{l}32.282 \\
44.705 \\
76.987\end{array}$ & $\begin{array}{l}15 \\
16\end{array}$ & $\begin{array}{r}32.282 \\
2.980\end{array}$ & 10.832 & $.005^{*}$ \\
\hline
\end{tabular}

Academic Performance Variables

I collected descriptive statistics on the four dependent variables of this research. As reported in Table 7, I determined and reported the means and standard scores for the Mathematics, Science, Reading, and Writing components of the CAPT.

The findings indicated population normality as reported in Table 8. Skewness and kurtosis measures for Math, Science, Reading, and Writing indicated normality of the sample for each test domain as all scores fell between $+/-1$, and all standard error measures were low. 
Table 7

Means and Standard Deviations on Achievement Variables

\begin{tabular}{lccc}
\hline & & $\begin{array}{c}\text { Standard } \\
\text { deviation }\end{array}$ & Range \\
\hline CAPT variables & Mean & 15.1 & $210.7-254.9$ \\
Sathematics & 237.56 & 16.3 & $200.9-251.1$ \\
Reading & 234.73 & 11.2 & $206.9-248.8$ \\
Writing & 233.10 & 8.5 & $208.2-247.1$ \\
\hline
\end{tabular}

Table 8

Achievement Sample Normality Descriptors

\begin{tabular}{lrrrr}
\hline & Math & Science & Reading & Writing \\
\hline Skewness & -.841 & -.842 & -.575 & -.414 \\
Std. error of skewness & .090 & .090 & .090 & .090 \\
Kurtosis & -.547 & -.740 & -.614 & .126 \\
Std. error of kurtosis & .181 & .181 & .181 & .181 \\
\end{tabular}

To further define the parameters of my results, I conducted four analysis of variance tests (ANOVAs) to determine the impact of socioeconomic status of schools on achievement. These findings provided supplemental information about my research outcomes. Five of the 17 schools were identified as "Title 1" status based on the free and reduced lunch count at each of those schools. I compared student achievement at Title 1 
and non-Title 1 schools in reading, writing, science and mathematics. The following tables indicate the results of my findings.

The results indicated a significant difference in mean scores between Title 1 and non-Title 1 schools, as noted in Table 9. The $F$ ratio of 7.547 provided a $p$ value significance of .000 at the alpha level of .05 . The results indicated a significant influence of Title 1 school identification on the achievement results in mathematics.

The results indicated a significant difference in mean scores between Title 1 and non-Title 1 schools, as noted in Table 10. The $F$ ratio of 91.068 provided a $p$ value significance of .000 at the alpha level of .05 and indicated a significant influence of Title 1 school identification on the achievement results in science.

The results indicated a significant difference in mean scores between Title 1 and non-Title 1 schools, as noted in Table 11 . The $F$ ratio of 27.141 provided a $p$ value significance of .000 at the alpha level of .05 and indicated a significant influence of Title 1 school identification on the achievement results in reading.

Table 9 ANOVA Title 1 Relationship to CAPT Mathematics Performance

$\begin{array}{lllll}S S & d f & M & \text { Sig. }\end{array}$

\begin{tabular}{lcrrrrr}
\hline Math & Between & Combined & & & & \\
Title 1 & groups & 2814.697 & 1 & 2814.697 & 7.547 & $.000^{*}$ \\
& Within & & & & & \\
& groups & & 887.972 & 15 & 59.198 & \\
& Total & 3702.669 & 16 & & & \\
& & & & & & \\
& & & & &
\end{tabular}

${ }^{*} p<.05$. 
Table 10

ANOVA Title 1 Relationship to CAPT Science Performance

\begin{tabular}{|c|c|c|c|c|c|c|c|}
\hline & & & $S S$ & $d f$ & $M S$ & $F$ & Sig. \\
\hline $\begin{array}{l}\text { Science } \\
\text { Title } 1\end{array}$ & $\begin{array}{c}\text { Between } \\
\text { groups } \\
\text { Within } \\
\text { groups } \\
\text { Total }\end{array}$ & Combined & $\begin{array}{r}4009.904 \\
660.479 \\
4670.382\end{array}$ & $\begin{array}{l}15 \\
16\end{array}$ & $\begin{array}{r}4009.904 \\
44.032\end{array}$ & 91.068 & $.000^{*}$ \\
\hline
\end{tabular}

Table 11

ANOVA Title 1 Relationship to CAPT Reading Performance

\begin{tabular}{|c|c|c|c|c|c|c|c|}
\hline & & & $S S$ & $d f$ & $M S$ & $F$ & Sig. \\
\hline $\begin{array}{l}\text { Reading } \\
\text { Title } 1\end{array}$ & $\begin{array}{l}\text { Between } \\
\text { groups } \\
\text { Within } \\
\text { groups } \\
\text { Total }\end{array}$ & Combined & $\begin{array}{r}1468.320 \\
811.485 \\
2279.805\end{array}$ & $\begin{array}{l}15 \\
16\end{array}$ & $\begin{array}{r}1468.320 \\
54.099\end{array}$ & 27.141 & $.000^{*}$ \\
\hline
\end{tabular}

The results indicated a significant difference in mean scores between Title 1 and non-Title 1 schools, as noted in Table 12. The $F$ ratio of 12.801 provided a $p$ value significance of .003 at the alpha level of .05 and indicated a significant influence of Title 1 school identification on the achievement results in writing.

Despite the homogeneous criteria for student entry into the school district, the common curriculum and curriculum assessments across schools, and standard teacher 
Table 12

ANOVA Title 1 Relationship to CAPT Writing Performance

\begin{tabular}{|c|c|c|c|c|c|c|c|}
\hline & & & $S S$ & $d f$ & $M S$ & $F$ & Sig. \\
\hline $\begin{array}{l}\text { Writing } \\
\text { Title } 1\end{array}$ & $\begin{array}{c}\text { Between } \\
\text { groups } \\
\text { Within } \\
\text { groups } \\
\text { Total }\end{array}$ & Combined & $\begin{array}{r}814.467 \\
1509.529\end{array}$ & $\begin{array}{l}15 \\
16\end{array}$ & 695.063 & 12.801 & $.003^{*}$ \\
\hline
\end{tabular}

certification for subject matter instruction, the effects of socioeconomic status on these findings are noteworthy and limit the generalizability of these findings. The results, however, confirm the impact of socioeconomic status on student achievement.

\section{Pearson Product-Moment Correlations}

I executed a second preliminary statistical procedure. Because the primary statistical procedure was a multiple regression, I calculated Pearson Product-Moment Correlations to determine the relationship between predictor variables (CTEBS Instruction, CTEBS Discipline, and CTEBS Total Score) and each of the respective criterion variables (CAPT Mathematics, Science, Reading, and Writing). In Table 13, I report the inter-correlations among all variables.

Results showed positive correlations across all variable measures. All of the Pearson Product-Moment Correlations were statistically significant at the .05 level; these results may have been based partly on a large sample size of 730 subjects. To determine if the results were biased by the large sample, I also ran the statistics at the .01 level. The 
Table 13

Inter-correlations of Predictor and Criterion Variables

\begin{tabular}{lccc}
\hline & $\begin{array}{c}\text { CTEBS } \\
\text { instruction }\end{array}$ & $\begin{array}{c}\text { CTEBS } \\
\text { discipline }\end{array}$ & $\begin{array}{c}\text { CTEBS } \\
\text { total score }\end{array}$ \\
\hline Math & $.08^{* *}$ & $.15^{* *}$ & $.12^{* *}$ \\
Science & $.11^{* *}$ & $.17^{* *}$ & $.15^{* *}$ \\
Reading & $.16^{* *}$ & $.17^{* *}$ & $.18^{* *}$ \\
Writing & $.13^{* *}$ & $.12^{* *}$ & $.13^{* *}$ \\
CTEBS instruction & 1.00 & $.70^{* *}$ & $.92^{* *}$ \\
CTEBS discipline & $.70^{* *}$ & 1.00 & $.93^{* *}$ \\
CTEBS total score & $.92^{* *}$ & $.93^{* *}$ & 1.00 \\
\hline$* p<.05 . * *<.01$. & & & \\
\hline
\end{tabular}

results were significant at this level. In viewing correlations between collective-efficacy and achievement, the positive correlations suggested that teachers with higher collectiveefficacy scores were found at schools with higher CAPT scores. Teachers with lower collective-efficacy scores were found at schools with lower CAPT scores.

Predictor variables should have low correlations with each other but high correlations with the criterion variable. In the case of this dissertation research, the predictor variables were highly inter-correlated. The CTEBS Instruction and the CTEBS Discipline Subscales had a high and positive correlation of .70 (r). Each was highly correlated with the Total Score. The CTEBS Instruction Subscale was correlated $.92(r)$ with the CTEBS Total Score. The CTEBS Discipline Subscale was correlated $.93(r)$ with 
the Total Score. These results signified that one of the three predictor variables would likely emerge as a singular predictor since variance among the three was shared.

As a precautionary and confirmatory measure, I conducted a factor analysis of the collective-efficacy data in response to the inter-collinearity of those data. The extraction method used was Principal Component Analysis, and the rotation method was completed through Varimax with Kaiser Normalization. The rotation was completed in three iterations. Two components were recognized as relevant factors since all other components had an eigenvalues of less than 1.0 (indicating that the variance accounted for less than for the original variable). The two components accounted for $64 \%$ of the variance as illustrated in Table 14.

Table 14

CTEBS Total Variance Explained

\begin{tabular}{|c|c|c|c|c|c|c|}
\hline \multirow[b]{2}{*}{ Component } & \multicolumn{3}{|c|}{ Initial eigenvalues } & \multicolumn{3}{|c|}{$\underline{\text { Rotation sums of squared loadings }}$} \\
\hline & Total & $\begin{array}{c}\% \text { of } \\
\text { variance }\end{array}$ & $\begin{array}{c}\text { Cumulative } \\
\%\end{array}$ & Total & $\begin{array}{c}\% \text { of } \\
\text { variance }\end{array}$ & $\begin{array}{c}\text { Cumulative } \\
\%\end{array}$ \\
\hline 1 & 6.580 & 53.817 & 53.817 & 4.226 & 35.220 & 35.220 \\
\hline 2 & 1.247 & 10.393 & 64.210 & 3.479 & 28.989 & 64.210 \\
\hline 3 & 0.797 & 6.640 & 70.850 & - & - & - \\
\hline 4 & 0.691 & 5.755 & 76.604 & - & - & - \\
\hline 5 & 0.541 & 4.507 & 81.112 & - & - & - \\
\hline 6 & 0.470 & 3.916 & 85.028 & - & - & - \\
\hline 7 & 0.416 & 3.468 & 88.496 & - & - & - \\
\hline 8 & 0.352 & 2.937 & 91.433 & - & - & - \\
\hline 9 & 0.311 & 2.588 & 94.021 & - & - & - \\
\hline 10 & 0.297 & 2.477 & 96.498 & - & - & - \\
\hline 11 & 0.258 & 2.151 & 98.498 & - & - & - \\
\hline 12 & 0.162 & 1.351 & 100.000 & - & - & - \\
\hline
\end{tabular}


As illustrated in Table 15, each item except Item 3 of the CTEBS loaded most heavily on the factors of Instruction (Component 1) and Discipline (Component 2) set forth by the test developer. A value of .4 or higher is considered adequate for loading on a given factor. These results support the reliability of the data set as measured across the school district and the overall validity of the test instrument used.

The distribution of values was highly adequate for the use of factor analysis. The Kaiser-Mayer-Olkin (KMO) Test generated a score of .913. Based on Kaiser's interpretation, a score of $>.9$ is "marvelous" (SPSS, 2005, p. 256) and illustrated the level of distribution quality for this analysis.

Table 15

CTEBS Rotated Component Matrix

CTEBS variables

$\frac{\text { Component }}{2}$

Item 1 instruction

.752

.303

Item 2 instruction

.725

.297

Item 3 discipline

.577

.445

Item 4 discipline

.500

.571

Item 5 instruction

.849

.168

Item 6 instruction

.839

.205

Item 7 discipline

.239

.785

Item 8 discipline

.181

.865

Item 9 instruction

.743

.344

Item 10 discipline

.259

.783

Item 11 instruction

.533

.453

Item 12 discipline

.368

.634 
Additionally, this table indicated the item relationship to the two measured collective-efficacy factors examined through this research: (a) instruction, and (b) discipline. Test developers Tschannen-Moran and Barr (2004) indicated that

in factor analysis, the 12 items loaded on one factor, with factor loadings that ranged from .79 to .58 . When the two factors were specified, the rotated factors divided along the predicted content, with factor loadings on the 6 items in the instructional strategies subscale ranging from .78 to .67 and the 6 items in the student discipline subscale ranging from .78 to .64 . (p. 188)

This instrument showed instructional-strategy-subscale reliability of .94, studentdiscipline-subscale reliability of .96 , and the 12-item scale demonstrated reliability of .97 .

\section{Primary Statistical Analysis}

I conducted four multiple regression analyses to address the four null hypotheses. The criterion or dependent variable (Y) was each of the four academic performance measures (Math, Science, Reading, and Writing). The vector of predictor variables was the two subscales of the Collective Efficacy test (Instruction and Discipline) and the Total Score. Specifically, these were the Instructional subscale (X1), the Discipline subscale (X2), and the Total Score (X3). All of the three were independent or predictor variables.

Given the high inter-correlation between predictors, I executed the four multiple regression procedures in a stepwise procedure in which the predictor variable that explained the most variance in the dependent variable emerged first, and then subsequent variables entered the regression equation. 


\section{Hypothesis Testing}

Null Hypothesis 1

Null Hypothesis 1: Academic performance on the Mathematics Component of the Connecticut Academic Performance Test (CAPT) cannot be predicted by a vector of scores consisting of CTEBS Instructional subscale, the CTEBS Discipline subscale, or the Total Score on the CTEBS.

The first null hypothesis was tested and rejected through use of a stepwise multiple regression. The independent variables were the Instructional and Discipline subscales of the CTEBS and the Total Score. The results as shown in Table 16 documented that the Discipline subscale of the CTEBS was the most effective predictor of the Mathematics CAPT score. The high inter-correlations among the predictor variables accounted for this result; only one predictor variable emerged (Discipline subscale). A multiple $R$ of .145 was obtained which accounted for $2 \%$ of the variance. The generated regression equation was as follows:

Math CAPT Score $(\hat{Y})=.31($ Discipline Score $)+224$.

Table 16

Hierarchical Regression Analysis of a Set of Predictor Variables Explaining the Variance in Mathematics Score on the CAPT $(N=730)$

\begin{tabular}{|c|c|c|c|c|c|}
\hline $\begin{array}{l}\text { Independent } \\
\text { variable }\end{array}$ & Multiple $R$ & $R^{2}$ & Adj. $R^{2}$ & $F$ & Sig. \\
\hline $\begin{array}{l}\text { Discipline } \\
\text { subscale }\end{array}$ & .145 & .021 & .020 & 15.56 & $.000^{*}$ \\
\hline
\end{tabular}




\section{Null Hypothesis 2}

Null Hypothesis 2: Academic performance on the Science Component of the Connecticut Academic Performance Test (CAPT) cannot be predicted by a vector of scores consisting of CTEBS Instructional subscale, the CTEBS Discipline subscale, or the Total Score on the CTEBS.

The second null hypothesis was tested and rejected through use of a stepwise multiple regression. The independent variables were the Instructional and Discipline subscales of the CTEBS and the Total Score. The results in Table 17 document that the Discipline subscale of the CTEBS was the most effective predictor of the Science CAPT score. The high inter-correlations among the predictor variables accounted for this result; only one predictor variable emerged. A multiple $R$ of .168 was obtained which accounted for $2.8 \%$ of the variance. The generated regression equation was as follows:

Science CAPT Score $(\hat{Y})=.38($ Discipline Score $)+218$.

Table 17

Hierarchical Regression Analysis of a Set of Predictor Variables Explaining the Variance in Science Score on the CAPT $(N=730)$

\section{Independent} variable Multiple $R$

$R^{2}$

Adj. $R^{2}$

F

Sig.

Discipline
subscale

.168

.028

.027

21.09

$.000^{*}$

${ }^{*} p<.05 .{ }^{*} p<.01$. 


\section{Null Hypothesis 3}

Null Hypothesis 3: Academic performance on the Reading Component of the Connecticut Academic Performance Test (CAPT) cannot be predicted by a vector of scores consisting of CTEBS Instructional subscale, the CTEBS Discipline subscale, or the Total Score on the CTEBS.

The third null hypothesis was tested and rejected through use of a stepwise multiple regression. The independent variables were the Instructional and Discipline subscales of the CTEBS and the Total Score. The results in Table 18 document that the Total Score of the CTEBS was the most effective predictor of the Reading CAPT score. The high inter-correlations among the predictor variables accounted for this result; only one predictor variable emerged. A multiple $R$ of .178 was obtained which accounted for $3.2 \%$ of the variance. The generated regression equation was as follows:

Reading CAPT Score $(\hat{Y})=.16($ Total Score $)+219$.

Table 18

Hierarchical Regression Analysis of a Set of Predictor Variables Explaining the Variance in Reading Score on the CAPT $(N=730)$

Independent variable Multiple $R$

Adj. $R^{2}$

Adj. $R^{2}$

F

Sig.

Total score on the CTEBS

.032

.030

23.91

$.000^{*}$

${ }^{*} p<.05 .{ }^{* *} p<.01$. 
Null Hypothesis 4

Null Hypothesis 4: Academic performance on the Writing Component of the Connecticut Academic Performance Test (CAPT) cannot be predicted by a vector of scores consisting of CTEBS Instructional subscale, the CTEBS Discipline subscale, or the Total Score on the CTEBS.

The fourth null hypothesis was tested and rejected through use of a stepwise multiple regression. The independent variables were the Instructional and Discipline subscales of the CTEBS and the Total Score. The results, as evidenced in Table 19, document that the Discipline subscale of the CTEBS was the most effective predictor of the Writing CAPT score. The high inter-correlations among the predictor variables accounted for this result; only one predictor variable emerged. A multiple $R$ of .130 was obtained which accounted for $1.7 \%$ of the variance. The generated regression equation was as follows:

Writing CAPT Score $(\hat{Y})=.09($ Total Score $)+224$.

Table 19

Hierarchical Regression Analysis of a Set of Predictor Variables Explaining the Variance in Writing Score on the CAPT $(N=730)$

\begin{tabular}{|c|c|c|c|c|c|}
\hline $\begin{array}{l}\text { Independent } \\
\text { variable }\end{array}$ & Multiple $R$ & $R^{2}$ & Adj. $R^{2}$ & $F$ & Sig. \\
\hline $\begin{array}{c}\text { Total score on } \\
\text { the CTEBS }\end{array}$ & .130 & .017 & .015 & 12.46 & $.000^{*}$ \\
\hline
\end{tabular}




\section{Summary}

In this chapter, I provided an explanation and summation of the study findings. First, descriptive statistics illustrated the population characteristics for both independent and dependent variable samples. Teacher and student samples were large in number. Teacher responses to the Collective Efficacy Belief Scale totaled 730 and represented $71 \%$ of the total district-wide teaching staff. Student achievement scores represented over $98 \%$ of the 1,273 student population of the district.

Next, I explained preliminary statistical analyses. Descriptive statistics on the collective-efficacy variable provided means and standard deviations for all CTEBS items, Discipline and Instruction Subscales and Total Test. These results indicated normality of the distribution. Descriptive statistics on the achievement variable provided means and standard deviations for CAPT Math, Science, Reading, and Writing. Heterogeneity of the distribution was determined through analyses of variance between Title 1 and nonTitle 1 schools in CAPT Mathematics, Science, Reading, and Writing and through analyses of variance in CTEBS Instruction and Discipline factors. Pearson ProductMoment Correlations were then conducted to determine the relationship between predictor variables (CTEBS Instruction, CTEBS Discipline, and CTEBS Total Score) and each of the respective criterion variables (CAPT Mathematics, Science, Reading, and Writing). My analysis of the results explained the correlation relationships between the variables. Positive correlations were evidenced between each predictor variable and each criterion variable. High degrees of inter-correlation between predictor variables were discussed. Inter-correlations ranged from $.70(r)$ to $.93(r)$. To support the validity of findings, inter-collinearity of CTEBS components was addressed through confirmatory 
factor analysis. Results showed that all but one item fell within expected domains of instruction and discipline based on the original factor analysis established in test construction.

Third, I described primary statistical analyses. I conducted four Multiple Regression analyses to address each of the four null hypotheses. I provided the rationale for use of a stepwise procedure. Given the inter-collinearity of the predictor variables, one predictor variable emerged as a singular predictor in each case.

Hypothesis testing resulted in my rejection of all four null hypotheses.

Achievement in math and science were most effectively predicted by the collective teacher beliefs around school discipline. Reading and writing achievement were most effectively predicted by the overall perceptions of teachers' collective-efficacy. 


\title{
CHAPTER 5
}

\author{
SUMMARY, CONCLUSIONS, IMPLICATIONS, AND \\ RECOMMENDATIONS
}

\section{Introduction}

School leaders face daunting challenges in the provision of services that enhance student learning. Student achievement is dependent on quality teaching, yet many educators appear resistant to learning and applying innovative instructional approaches. Additional research is needed to determine how teachers learn new instructional approaches and on the work conditions that impact teacher acquisition of new skills (Elmore et al., 1996; Pajares, 1996). Perceived collective-efficacy was one factor that impacts teacher instructional decisions (Tschannen-Moran \& Barr, 2004). School leaders needed to consider the power of efficacious beliefs as they attempt to reform school practices.

My study provides new information on the relationship between collectiveefficacy and student achievement within the context of vocational-technical high-school settings. Although the direct relationship between collective-efficacy and student achievement had been established in traditional school settings (Bandura, 2001), the predictive value of collective-efficacy to aspects of student achievement in vocationaltechnical high schools was not well documented in the literature (Vaz, 2006). 


\section{Purpose of the Study}

The purpose of my study was to examine the relationship between collectiveefficacy beliefs of teachers and student achievement. The study is important to school leaders because it contributes information about teaching beliefs and practices that may impact student learning outcomes. I examined the collective-efficacy beliefs of academic and trade teachers in 17 Connecticut technical high schools and the relationship between those beliefs to student achievement on the Connecticut Academic Performance Test. My study determined relationships between (a) teachers' overall perceptions of collective-efficacy and student achievement, (b) teachers' perceptions of their collective instructional efficacy to student achievement, and (c) teachers' perceptions of their collective discipline efficacy to student achievement. For each collective-efficacy domain, I explored the relationships to mathematics, science, reading, and writing achievement.

This chapter provides a review of the research problem and associated research questions. Furthermore, this chapter addresses implications of the study, recommendations for future use, and conclusions.

\section{Overview of the Literature Review}

The literature review in chapter 2 identified key theories and studies relevant to the examination of collective-efficacy and student achievement. Founded in Social Cognitive Theory, the construct of efficacy had been studied in education and other social science areas, including physical and emotional health, team-building, career-building, and productivity. The sources of efficacious beliefs were derived from social, vicarious, physiological, or mastery learning experiences. This review identified studies illustrating 
the relationship of efficacy to each domain. It described the underpinnings of Social Cognitive Theory and the relationship between theory constructs and ongoing research.

Social Cognitive Career Theory described an extension of Social Cognitive Theory. Social Cognitive Career Theory was discussed as it is used to explore academic pursuits and vocational decisions. The review of literature around vocational school settings was addressed. Few studies in vocational high-school settings were noted in the literature. Nonetheless, the impact of efficacious beliefs by educators in those settings contributed to student performance.

The literature on teacher-efficacy identified the relationship between selfefficacious beliefs and student outcomes. Teachers with high efficacious beliefs about their power to manipulate achievement outcomes were confirmed through a multitude of studies. Teacher-efficacy impacted student learning across all subjects and grade levels. Furthermore, the impact of administration support played a role in developing efficacious beliefs. This literature review identified the instrumentation developed to measure efficacious beliefs.

The literature on collective-efficacy in school settings described the impact of educators' collective-efficacy beliefs on student achievement. Collective-efficacy illustrated the perceptions of an educator about the joint control of the school membership around achievement and related factors such as discipline, school climate, and learning community. Collective-efficacy beliefs contributed to student achievement across all content areas and grade levels. The literature review described test instruments developed to measure the collective-efficacy beliefs of educators. 


\section{Research Questions}

I addressed the following research questions:

1. Is there a relationship between the degree of perceived collective-efficacy and student achievement in mathematics?

2. Is there a relationship between the degree of perceived collective-efficacy and student achievement in science?

3. Is there a relationship between the degree of perceived collective-efficacy and student achievement in reading?

4. Is there a relationship between the degree of perceived collective-efficacy and student achievement in writing?

\section{Research Design}

In this study, I used multiple regression techniques to examine the relationships between collective-efficacy (independent variable) and student achievement (dependent variable). The sample I used to obtain data for the independent variable included teachers within academic and trade departments from 17 technical high schools. I measured the independent variable through use of a collective-efficacy questionnaire. Student achievement scores from the same schools provided my data for the dependent variable. I included the composite test scores for student achievement in science, math, writing, and reading on the Connecticut Academic Performance Test. I discussed specific instrumentation and statistical measures in chapter 3 . 


\section{Summary of Findings}

These results were confirmatory of previous research related to Social Cognitive Theory. Based on my research questions, the findings were as follows:

Research question 1: Is there a relationship between the degree of perceived collective-efficacy and student achievement in mathematics? A significant relationship between teacher perceptions of collective-efficacy and student achievement in mathematics was evidenced. Achievement in math was most effectively predicted by the collective teacher beliefs around school discipline.

Research question 2: Is there a relationship between the degree of perceived collective-efficacy and student achievement in science? A significant relationship between teacher perceptions of collective-efficacy and student achievement in science was evidenced. Achievement in science was most effectively predicted by the collective teacher beliefs around school discipline.

Research question 3: Is there a relationship between the degree of perceived collective-efficacy and student achievement in reading? A significant relationship between teacher perceptions of collective-efficacy and student achievement in reading was evidenced. Achievement in reading was most effectively predicted by the overall (combined instructional and behavioral) collective-efficacy beliefs of teachers.

Research question 4: Is there a relationship between the degree of perceived collective-efficacy and student achievement in writing? A significant relationship between teacher perceptions of collective-efficacy and student achievement in writing was evidenced. Achievement in writing was most effectively predicted by the overall (combined instructional and behavioral) collective-efficacy beliefs of teachers. 
In summary, a significant relationship between teacher perceptions of collectiveefficacy and student achievement in mathematics, science, reading, and writing was evidenced. Achievement in math and science was most effectively predicted by the collective teacher beliefs around school discipline. Reading and writing achievement was most effectively predicted by the overall perceptions of teachers' collective efficacy. Additionally, the results supported the relationship between socioeconomic status of schools and student achievement. Collective-efficacy beliefs about student discipline were lower at schools with lower socioeconomic status.

\section{Conclusions and Implications}

The major conclusions I drew from this study centered on the relationship between teacher beliefs, teaching practices, and student achievement. These conclusions have major implications for school leadership.

Conclusion 1: The findings supported the underpinnings of Social Cognitive Theory. Efficacious beliefs of teachers impact student achievement. The collective beliefs around efficacy of educators across a school are important for leaders to consider in developing safe, orderly, and productive learning communities within schools.

Conclusion 2: The perception of collective-efficacy pertaining to school discipline was a predictive factor in mathematics and science achievement at the secondary-school level. Control over discipline may be more valued than instructional control given the safety and managerial issues of students working with tools, knives, machines, and other dangerous elements at vocational schools. Leaders might explore how teacher assurance of disciplinary control may allow for greater time and concentration of efforts around instruction. 
Conclusion 3: Instructional efficacy was not a significant factor in student achievement when measured without the mediating effects of behavioral efficacy perceptions. When combined with discipline beliefs, a significant relationship between overall perceptions of collective-efficacy and achievement in reading and writing were noted. School leaders might consider that a combination of instructional and behavioral supports is needed for teacher empowerment.

Conclusion 4: The socioeconomic status of students had a significant impact on student achievement and on the collective-efficacy beliefs of teachers around discipline.

Conclusion 5: The Collective-Efficacy Belief Scale met confirmatory factor analysis examination. All but one item loaded under expected components of Instruction and Discipline. The instrument might be used in further studies at vocational-technical high schools by leaders seeking out efficacy and achievement factors. However, given the inter-correlations obtained through the instrument, additional measures may be warranted.

\section{Recommendations}

I offer recommendations from this study for further research and for direct application of findings by leaders in vocational school settings.

\section{Recommendations for Further Research}

1. It is important to continue research that investigates the relationship of collective-efficacy to achievement in vocational school settings through qualitative and quantitative measures. Few studies have addressed the constructs of efficacy within the unique confines of a vocational school structure. 
2. The efficacious beliefs of trade teachers might be examined in isolation to determine whether the beliefs of academic teachers in schools are different from those of teachers responsible for the vocational skill development of students. The factors around the development of efficacious beliefs for various teacher populations may provide important information for school leaders to use in addressing school reform efforts.

3. The efficacious beliefs of specific academic and trade departments might be examined to further define the conditions under which efficacious beliefs are developed. The implications of those beliefs around student achievement factors might be explored.

4. The efficacious beliefs around discipline might be examined through further research. The conditions under which teachers perceive strong efficacy around discipline may provide additional insights into the development of safe and orderly schools. Issues such as suspension/expulsion rates, detentions, and number of times students are sent out of class may need to be addressed if instruction is to be improved.

5. Additional research that measures the sources of collective-efficacy beliefs (social persuasion, mastery learning, vicarious experiences, physiological/emotional sources) in vocational settings may be warranted. Given the unique nature of these institutions, school leaders have few sources of information to assist in developing strong professional learning communities.

6. Additional studies that isolate school factors related to collective-efficacy might be addressed. School characteristics such as the impact of socioeconomic status, feeder school patterns, percentage of students with special needs coming from feeder schools, and other school characteristics might be considered. 
7. Additional instruments that measure collective-efficacy within the context of vocational school settings may provide deeper insight into the factors that capture efficacious belief development and enactments.

\section{Recommendations for School Leaders}

As a result of this research, instructional leaders in vocational-technical high schools may apply new knowledge of the relationships between collective-efficacy and student achievement to create stronger professional learning environments in their schools.

1. Since teacher perceptions of collective-efficacy appear to have an impact on implementation of instructional pedagogy, it is important that school leaders actively seek out ways to measure and support such processes. Organizations might provide explicit opportunities for teachers and administrators to measure and develop their sense of efficacy and beliefs about student learning. Discrepancies between teachers' articulated beliefs and practices and their actual instructional performance could be noted and acted on by school leaders through appropriate, supportive measures.

2. School leaders need to develop strong work cultures in schools. In such environments, teachers are able to achieve school expectations for collegial, reflective practices related to instruction. In professional learning communities, teaching practices and beliefs about instruction become public. Therefore, efficacious beliefs are more readily addressed.

3. School discipline efforts and discussions with teachers around related administrative support, school practices, and consistency of communications may assist in building stronger levels of collective-efficacy. Since collective-efficacy beliefs around 
discipline have a significant impact on achievement, it is important that school leaders build such beliefs that are integrated by the instructional and support staff of the school and within the school community itself. The provision of comprehensive professional development in professional learning communities, social skill development, and student behavior may contribute to these efforts.

4. Attention to the collective-efficacy beliefs of the larger school community is important to school leaders. Parents, community action groups, and other key supports to the schools might be invited to participate in activities and long-term processes that build collective-efficacy beliefs and instructional empowerment. 
APPENDIX 
APPENDIX A

CONNECTICUT TECHNICAL HIGH SCHOOLS LESSON PLAN 


\section{Guiding Questions for Lesson Plan Development}

What are the important outcomes I want all students to learn as a result of this lesson? What background knowledge/skills do students need to have to successfully master the lesson content?

What types of learning strategies, skills and modifications (reading, note taking, highlighting as you read, writing, listening, etc.) do students need to use to successfully participate in this lesson AND where in the lesson will the specific strategy be taught or reviewed?

What types of activities will I incorporate in my explicit direct teaching (modeling, small groups, brainstorming, activating prior knowledge, problem solving, etc.) to assure that ALL students' needs/interests/talents are met?

What are effective and appropriate ways (oral presentations, tests, reports, graphs, etc.) to evaluate how well students learned the objective?

Learning Objective:

Reference to Curriculum Goals(s) and Corresponding Learner Outcome (e.g., Goal I, L.O. I.2):

*Schema Activator (activity designed to stimulate the student's interest and independent thinking about the learning topic; activates prior knowledge):

**Explicit/Direct Teaching Strategies:

**Practice Activity:

**Application/Assessment:

*Closure:

**Reflections based on student performance; necessary changes/modifications for future use:

*Required for each lesson

** Dependent upon learning sequence within the unit. 
APPENDIX B

CONNECTICUT TECHNICAL HIGH SCHOOL SYSTEM COURSE OPTIONS 


\section{Connecticut Technical High School System Course Options}

\section{Technology Clusters}

The cluster is the primary unit of organization at the Connecticut Technical High Schools. Utilizing the national definition of technology clusters, the six career clusters are as follows:

$\begin{array}{ll}\text { I. } & \text { Retail, Hospitality and Tourism Cluster } \\ \text { II. } & \text { Construction Cluster } \\ \text { III. } & \text { Manufacturing Cluster } \\ \text { IV. } & \text { Transportation Cluster } \\ \text { V. } & \text { Computer Technologies Cluster } \\ \text { VI. } & \text { Health Technology Cluster }\end{array}$

Each technical program has a specific three-year program of study that outlines all academic and technical coursework required for students enrolled in that particular cluster. The career programs taught within each cluster are as follows:

\section{Retail, Hospitality and Tourism Cluster}

The Hospitality and Tourism Cluster is designed to create an appreciation of the service trades. Programs provide students with theoretical knowledge and skills for entry-level employment in the management, marketing and operation of restaurants, bakeries, lodging and travel-related services. Also included in this cluster are programs providing students with skills in hairdressing/barbering and fashion design. Graduates find employment in a wide variety of service occupations or continue their studies at post-secondary institutions.

Baking

Culinary Arts

Fashion Technology

Hairdressing/Barbering

Hotel/Hospitality Technology

Retail Management and Entrepreneurship 


\section{Construction Cluster}

The Construction Cluster is designed to create an appreciation of the construction industry and develop entry level-skills within the industry. The program provides students with theoretical knowledge and skills for entry-level employment in the residential, commercial and industrial construction areas or in post-secondary institutions. Many opportunities for employment within the construction industry are available.

Architectural Technologies

Carpentry

Electrical

Heating Ventilation and Air Conditioning (HVAC)

Masonry

Plumbing and Heating

Plumbing, Heating and Cooling (Oliver Wolcott Tech only)

\section{Manufacturing Cluster}

The Manufacturing Cluster is comprised of interrelated industries that include the broad categories of manufacturing and assembling goods, drafting and design, machining and welding/fabrication. Many opportunities for employment and future professional development are possible within this cluster. Production planning and control, product and tooling design and manufacturing engineering are a few of the possible opportunities. Students also have the opportunity to continue their studies at postsecondary institutions.

\section{Computer-Aided Drafting and Design}

Electromechanical Technology

General Drafting and Design

Manufacturing Technology

Welding and Metal Fabrication 


\section{Transportation Cluster}

The Transportation Cluster prepares students to apply technical knowledge and skills in diagnostics, repair and maintenance of automotive and heavy-duty engines and equipment. Graduates enter the many opportunities for employment as automotive mechanics, diesel engine repair technicians, and in collision repair and refinishing. Students also have the opportunity to continue their studies at postsecondary institutions.

Automotive Collision, Repair and Refinishing

Automotive Technology

Diesel and Heavy Duty Equipment Repair

\section{Computer Technologies Cluster}

The Computer Technologies cluster prepares students to apply technical knowledge and skills designing, developing, managing and supporting hardware, software, multimedia and systems integration services. Also included in this cluster are programs providing training in electronics technology and graphic technology. Graduates enter a wide variety of hightechnology positions or continue their studies at postsecondary institutions.

\section{Electronics Technology}

Graphics Technology

Information Systems Technology

Digital Microprocessor Technician (One Year Program only at Bristol Technical Education Center)

\section{Health Technology Cluster}

The Health Technology Cluster is designed to provide a broad-based exposure and appreciation of health-related and early care and education occupations, as well as those in bioscience environmental technology. Programs provide students with theoretical knowledge and clinical skills in planning, managing and providing health care services, early care and education, and bioscience environmental technology research. Graduates may complete a competency credential or certification eligibility for entry-level employment in a variety of health-care settings or continue their studies at postsecondary institutions.

Bioscience Environmental Technology

Early Care and Education

Health Technology 


\section{DRAFT POWERED CURRICULA}

\section{Academic Offerings}

Art

Career Development

Computer Education

English

Health Education

Library Media

Mathematics

Music

Physical Education

Science

Social Studies

World Languages

\section{Technical Offerings}

Architectural Technologies

Carpentry

Computer-Aided Drafting and Design

Culinary Arts

Early Care and Education

Electrical

Electronics Technology

Fashion Technology

Graphics Technology

Hairdressing and Barbering

Health Technology

Heating, Ventilation, and Air

Condtitioning

Information Systems Technology

Manufacturing Technology

Masonry

Plumbing and Heating 
APPENDIX C

TEACHER CERTIFICATION REQUIREMENTS AND APPLICATION 


\section{JOB OPENINGS for School Instructional and Support Staff}

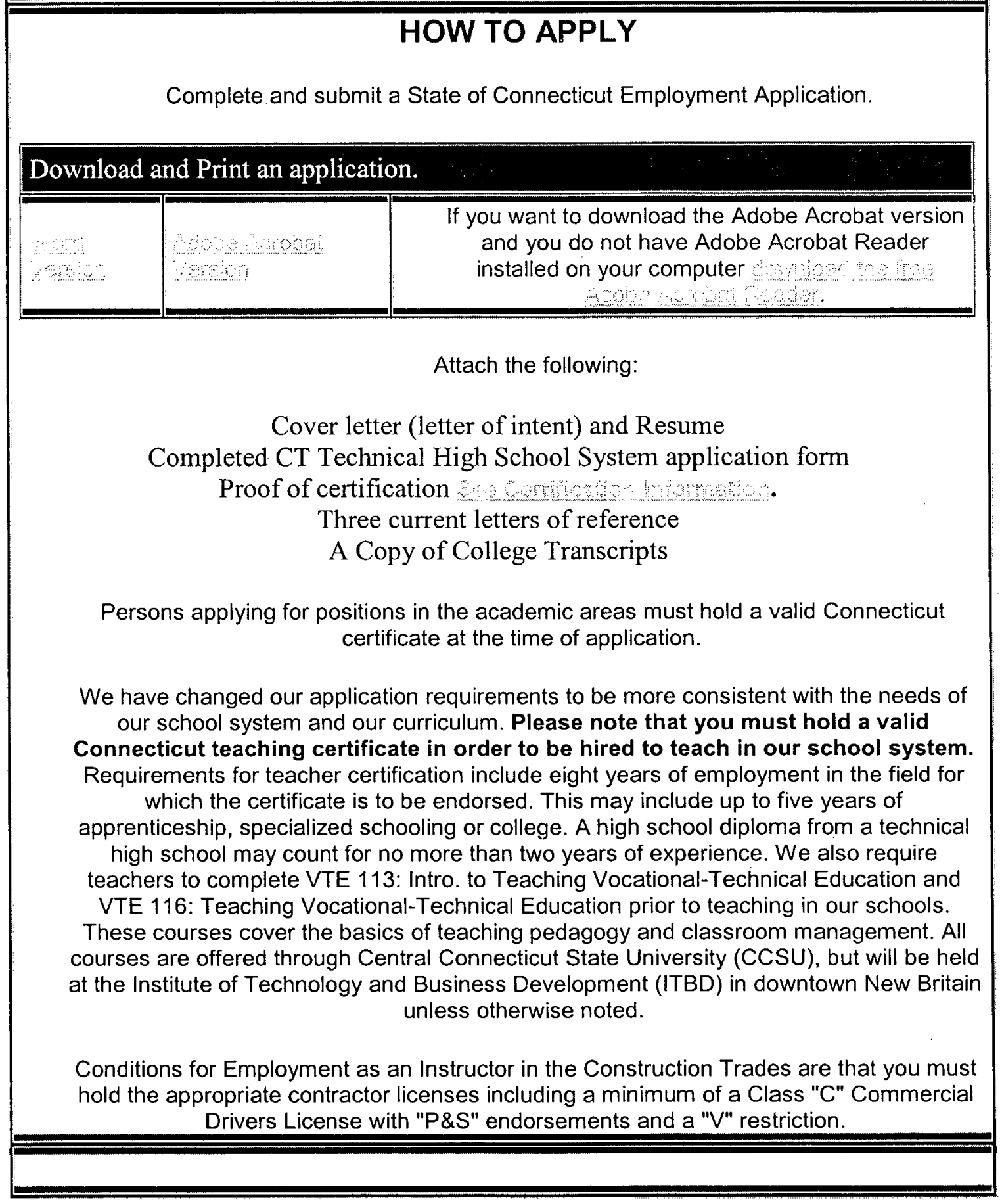




\section{Connecticut Technical High School System \\ Professional Employment Application}

\section{Application for Instructor and School Administrator Positions}

(Please type or print legibly in ink. Attach additional sheets as required.)

Thank you for your interest in the Connecticut State Department of Education, for its Technical High Schools. We invite outstanding educational leaders to apply for positions in our system. The Connecticut Technical High School system is a statewide system of 17 small high schools offering strong instruction in academics and a wide variety of trade technologies. $A$ new administrative team is developing/implementing new curriculum in both academic and trade areas and providing intensive professional development. A new scheduling model offers school more flexibility and students more electives. The position offers a competitive starting salary and state benefits.

Name

Soc. Sec. No.

Date
(Last)
(First)
(MI)

Address

Street

Telephone: Day: ( )

Eve: ( )

City State

Zip

Position Applying For:

Full-time Instructor

Part-time Day Instructor

Part-time Evening Instructor

Coach

Substitute Instructor

Principal

Assistant Principal
Subject(s)

Subject(s)

Subject(s)

Sport(s):

Subject(s):

E-mail:

DEMOGRAPHIC INFORMATION (Voluntary): In order to meet state and federal reporting requirements, we request that you voluntarily supply the following information on gender and race. This data will not be used for discriminatory purposes and will not be considered in the evaluation of your application.

$\mathrm{F}$

$\mathrm{M}$
American Indian/Alaskan Native

Asian/Pacific Islander

Black
Caucasian

Hispanic

Other, Specify: 
If you answer yes to questions $2,3, \mathrm{OR} 4$, explain on a separate sheet of paper and attach it to this application. Provide information concerning the jurisdiction of the conviction, pending charges, approximate date, nature of conviction or charges or circumstances of dismissal.

1. Are you legally authorized to work in the U.S.?

Yes No

2. Have you ever been convicted of a felony or any other criminal offense, either within or outside of the State of Connecticut?

Yes No

3. Are any criminal charges currently pending against you, either within or outside of the State of Connecticut?

Yes No

SPECIAL NOTE: You are not required to disclose the existence of any arrest, criminal charge or conviction, the records of which have been erased pursuant to Connecticut General Statutes $\S 46 \mathrm{~b}-146,54-$ $76 \mathrm{o}$, or $54-142 \mathrm{a}$. If your criminal records have been erased pursuant to one of these statutes, you may swear under oath that you have never been arrested. Criminal records that may be erased are records pertaining to a finding of delinquency or that a child was a member of a family with services needs (C.G.S. $\S 46 \mathrm{~b}-146$ ), an adjudication as a youthful offender (C.G.S. § 54-76o), a criminal charge that has been dismissed or nolled, a criminal charge for which the person has been found not guilty or a conviction for which the person received an absolute pardon (C.G.S. § 54-142a).

4. Have you ever been dismissed or discharged from a position?

Yes No

Please check the following schools you are interested in:

School Locator

\begin{tabular}{|ll|}
\hline Name of School & Location \\
\hline Emmett O'Brien & Ansonia \\
Bullard Havens & Bridgeport \\
Bristol T.E.C. & Bristol \\
Henry Abbott & Danbury \\
H.H. Ellis & Danielson \\
Ella T. Grasso & Groton \\
Eli Whitney & Hamden \\
A.I. Prince & Hartford \\
Howell Cheney & Manchester \\
Cheney Satellite & Enfield \\
Stratford-Aviation & Stratford \\
H.C. Wilcox & Meriden \\
Vinal & Middletown \\
Platt & Milford \\
E.C. Goodwin & New Britain \\
Norwich & Norwich \\
J.M. Wright & Stamford \\
Oliver Wolcott & Torrington \\
W.F. Kaynor & Waterbury \\
Windham & Willimantic \\
& \\
&
\end{tabular}




\section{CERTIFICATION/LICENSE INFORMATION:}

Are you currently certified to teach in Connecticut? Yes No

List teaching endorsements and expiration dates:

Subject/Endorsement No. Expires:

Subject/Endorsement No.

Expires:

Are you currently certified as an Administrator in Connecticut? Yes No

List endorsements and expiration dates:

Administrator/Endorsement No. Expires: Administrator/Endorsement No. Expires

If you are not currently certified, are you eligible for Connecticut certification? Yes No

List endorsements for which you are eligible:

List other states in which you are currently certified to teach:

List other states in which you are certified as an administrator:

Do you have tenured status in Connecticut under C.G.S. Sec. 10-151? Yes No

District in which you achieved tenure:

Date Tenured

Do you hold a valid driver's license? Yes No

In what state?

Do you hold a Commercial Driver's License (CDL)? Yes No Expires:

Do you hold a Public Passenger Transport Permit (PPTP)? Yes No Expires:

Do you hold any Trade Licenses? Yes No

List trade licenses and expiration dates:

Trade/Type

Expires:

Trade/Type

Expires:

Do you hold a current Connecticut Coaching Permit? Yes No Expires:

\section{MILITARY SERVICE:}

Are you a U. S. Veteran? Yes No If yes, list branch:

Dates of Service: From To 


\section{EDUCATIONAL INFORMATION:}

(Attach copies of graduate and undergraduate transcripts.)

Did you graduate from high school or receive a high school equivalency diplóma? Yes No

If yes, what's the name of the high school you graduated from

List all postsecondary school education. Attach additional sheets if needed.

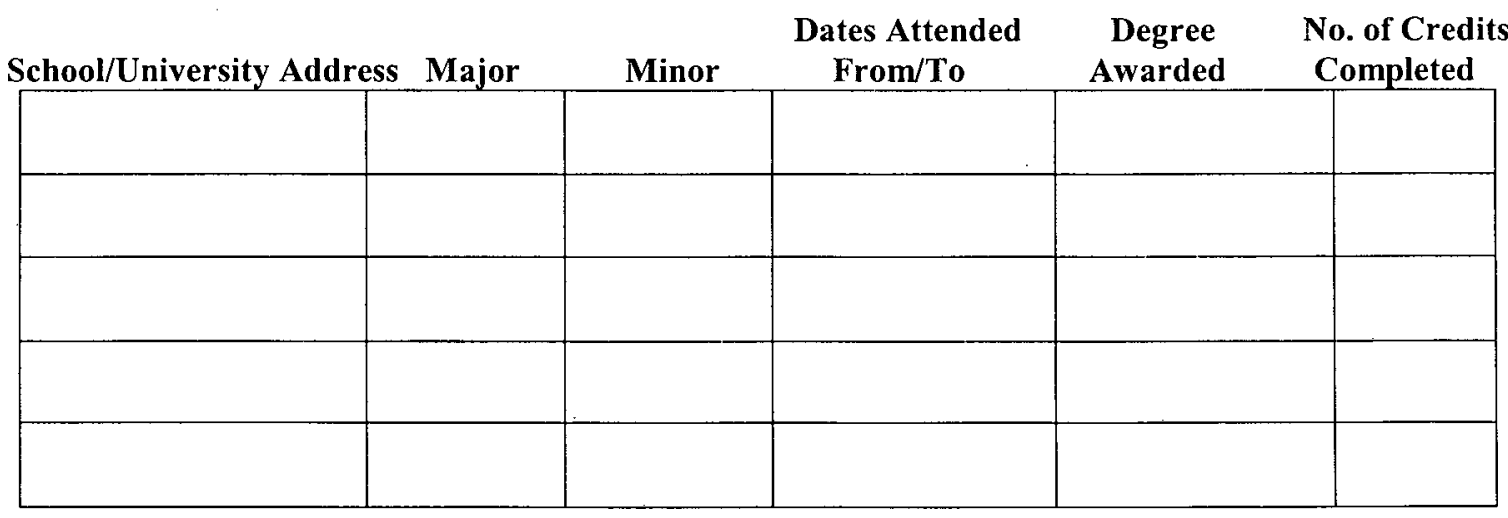

Other than English, in what language(s) are you fluent?

\section{TEACHING/ADMINISTRATIVE EXPERIENCE:}

(Please list positions in chronological order, with current or most recent position first). Attach additional sheets if necessary.

\section{Assignment/ Employment Dates Reason}

School Name \& Address Subject(s) Taught From/To for Leaving Supervisor Phone

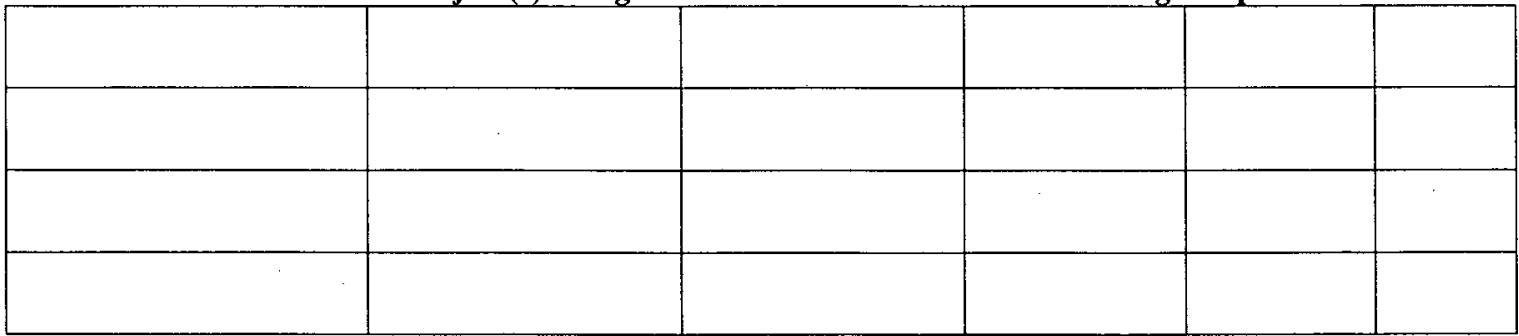

Mandatory-Briefly describe your background and qualification in relations to the position you are applying for: 
OTHER WORK EXPERIENCE:

Attach additional sheets if necessary. Employer Name/Address Job Title From/To Reason for Leaving Supervisor Name/Phone

\begin{tabular}{|l|l|l|l|l|}
\hline & & & & \\
\hline & & & & \\
\hline & & & & \\
\hline & & & & \\
\hline
\end{tabular}

If you are currently receiving pension benefits from either the Teachers Retirement System or the State Employees Retirement System, there are limits to the number of hours you may work without jeopardizing your pension. If you become an employee, you must advise us that you are a retiree. However, it is your responsibility to ensure that you do not exceed the allowable number of hours.

Are you related to any current employee of the Connecticut Department of Education or Connecticut Technical High School System (this includes related by marriage)? Yes No

If so, list name(s):

It is the policy of the Connecticut Technical High School System that no person shall be excluded from participation in, denied the benefits of, or otherwise discriminated against under any program, including employment, because of race, color, religious creed, sex, age, national origin, ancestry, marital status, sexual orientation, disability (including, but not limited to, mental retardation, past or present history of mental disorder, physical disability or learning disability), genetic information, or any other basis prohibited by Connecticut state and/or federal nondiscrimination laws. The Connecticut Technical High School System does not unlawfully discriminate in employment and licensing against qualified persons with a prior criminal conviction. Inquiries regarding the Connecticut Technical High School System's nondiscrimination policies and practices should be directed to William Turek, Title IX coordinator and 504 coordinator, (860) 807-2227, William.Turek@apo.state.ct.us and/or, regarding race, color, national origin, age, sex and/or disability, to the U.S. Department of Education, Office for Civil Rights, 33 Arch Street, Suite 900, Boston, Massachusetts $02110-$ 1491; telephone number (617) 289-0111; fax number (617) 289-0150; TTY/TDD (877) 521-2172. The Connecticut Technical High School System is an equal opportunity/affirmative action employer.

I understand that if I am employed by the Connecticut Technical High School System I will be required to submit to a state and national criminal history records check for a period of 30 days from my date of employment, and I will be required to submit to fingerprinting, at my expense, for purposes of submitting my fingerprints to the Federal Bureau of Investigation for a national criminal history records check. If my position requires me to obtain and maintain a Commercial Drivers License (CDL), I understand that it will require periodic drug and alcohol screening in accordance with federal regulation.

I hereby authorize any and all law enforcement agencies, current and former employers, credit agencies and academic institutions to supply any information regarding my background to the Connecticut Technical High School System and to its agents and employees, and I hereby release all such former employers, law enforcement agencies, credit agencies and academic institutions, their agents and employees from any liability arising from the supplying and use of such information.

I hereby certify that all of the information stated herein is accurate, complete and true to the best of my belief. I understand and agree that a false or dishonest answer to any question or the omission of pertinent information may be grounds for immediate termination of my employment.

Signature of Applicant

Date

The Connecticut State Department of Education is an Affirmative Action/Equal Opportunity Employer. 


\section{APPENDIX D}

CONNECTICUT TECHNICAL HIGH SCHOOL SYSTEM APPLICATION FOR ADMISSION 
Connecticut Technical High School System

Application for Admission

In order to be considered for admission to a Connecticut Technical High School, you must:

Fill out and sign this application and submit it to your school counselor as soon as possible; complete the Grade 7 Connecticut Mastery Test, if you have not completed the Grade 7 Connecticut Mastery Test (CMT) in Mathematics and Reading or you are a non-public school applicant you must arrange to take an alternative assessment with the Technical High School; and have no serious disciplinary offenses.

Your school must supply the Technical High School with the following data:

results of the Grade 7 Connecticut Mastery Test as reported on the Student Score Report;

a transcript of previous and current grades;

a record of previous and current attendance; and

a record of previous and current discipline infractions.

Applicants may include letters of recommendation (not required).

Incomplete applications will not be processed and returned to the applicant

\section{Instructions}

Complete this application with the appropriate signatures and return it to your school counselor, principal or teacher. Your school counselor will complete the sending school section of this application and forward your application, transcript of grades, attendance and discipline infractions to the Connecticut Technical High School. Letters of reference and/or personal statements from the student may be attached. 
This application requests information about your national origin, gender, racial or ethnic group, and primary language spoken in the home. Providing this information is voluntary. The information you do provide will be used for record-keeping purposes only; it will not be used as a factor in any action concerning education, activities or employment.

Student Name:

Sending School:

Name of Technical High School Applying To:

\section{Office Use Only}

Reading Test Score Mathematics Test Score Grades Attendance

\section{Personal Information}

To be completed by the student and parent/guardian

Full Name:

(Last)

Gender:

Male

Racial or Ethnic

Group:
(First)
Female

(Middle)

American Indian or Alaskan Native (1)

Asian American or Pacific Islander (2)

Black (3)

White (4)

Hispanic (5)

Residence

Address:

Box, Apartment, Street Name and Number)

(City or Town)

(State)

(Zip Code)

Mailing Address:

(If different from residence address) (Box, Apartment, Street Name and Number)

(City or Town)

(State)

(Zip Code)

Email Address: 
Primary Language:

What language did you learn to speak first?

What language is spoken the most by your parents/guardians or other persons living in your home?

What language do you speak the most at home?

Grade Applying For: 9 10 Trade/Technology You Wish to Learn: Other Trade/Technology Interests:

Current School:

Letter(s) of Recommendation Included:
Current Grade: Yes No

\section{RELEASE OF RECORDS}

I approve this application and I, the undersigned, hereby give permission for the School to release the

$$
\text { (name of school) }
$$

School records of to

$$
\text { (student name) }
$$
Technical High

(name of Technical High School)

School for the purpose of admission/placement at that school. Such records include, but are not limited to, course grades, discipline records, standardized test results, 504 Plans, IEP and/or PPT records, attendance records, school health records, records of extracurricular activities and psychological reports.

Date:

Signature of Parent/Guardian

Date:

Signature of Applicant 
It is the policy of the Connecticut Technical High School System that no person shall be excluded from participation in, denied the benefits of, or otherwise discriminated against under any program, including employment, because of race, color, religious creed, sex, age, national origin, ancestry, marital status, sexual orientation, or disability (including, but not limited to, mental retardation, past or present history or mental disorder, physical disability or learning disability), genetic information, or any other basis prohibited by Connecticut state and/or federal nondiscrimination laws. The Connecticut Technical High School System does not unlawfully discriminate in employment and licensing against qualified persons with a prior criminal conviction. Inquiries regarding the Connecticut High School System's nondiscrimination policies and practices should be directed to Dr. Abigail Hughes, Superintendent of Schools, Connecticut Technical High School System, 25 Industrial Park Road, Middletown, CT 06457, and/or, regarding race, color, national origin, age, sex and/or disability to the Office for Civil Rights, U.S. Department of Education, Boston, MA 02110-1491, telephone 617.289.0111, fax 617.289.0150, TTY/TDD 877.521.2172. The Connecticut Technical High School System is an equal opportunity/affirmative action employer.

\section{School Information to be Completed by the Sending School Incomplete applications will not be processed and will be returned to the applicant's parent/guardian.}

Student Name: Grade:

Academic Information

Please provide the following information, or attach a transcript with this information along with the student's Grade 7 CMT results.

\begin{tabular}{|l|c|c|}
\hline \multicolumn{1}{|c|}{ ACHIEVEMENT } & $\begin{array}{c}\text { Previous Grade } \\
\text { Final Average }\end{array}$ & $\begin{array}{c}\text { Current Grade } \\
\text { Term 1 }\end{array}$ \\
\hline Mathematics & & \\
\hline Science & & \\
\hline English & & \\
\hline Social Studies & & \\
\hline Absent Unexcused & & \\
\hline
\end{tabular}

The student's final transcript, ELL program records, 504 plan, special education records, and health records are required at the end of the year but no later than July 8 for all accepted applicants.

Acceptance is contingent upon successful completion of current grade and promotion to the next grade.

Student Behavior 
Please provide the following required discipline information on the above named student. If you answered yes to any of the questions below please attach the student's complete discipline record.

Has this student participated in a violent criminal offense, as determined by State Law, while in or on the grounds of a school? $\square$ Yes $\square$ No Has this student committed a gun-free schools violation (possession of a firearm or explosive device that resulted in expulsion)? $\square$ Yes $\square$ No

Has this student participated in an "other weapon" incident resulting in expulsion?

$\square$ Yes $\square$ No

Does this student have any other discipline infractions (dangerous or criminal offenses)? $\square$ Yes $\square$ No

\section{Leadership}

Has this student participated in any in-school or out-of-school leadership activities?

$\square$ Yes $\square$ No

If yes, please attach a statement from the student that details his/her participation in leadership activities. 1 to 3 Bonus Points

Has this student been identified as gifted or talented? If yes, please check.

Gifted $\square \quad$ Talented

\section{Special Education, 504 and Support Services}

Does the student receive any special education services? $\quad \square$ Yes $\quad \square$ No If yes, date of last triennial evaluation:

If yes, please describe:

Has the student been identified as 504 eligible and receive services? $\square$ Yes $\square$ No If yes, please describe:

Does the student receive any support services other than special education?

$\square$ Yes $\square$ No

If yes, please describe:

\section{ELL (English Language Learner) Support Services}

Does the student receive bilingual services? $\quad \square$ Yes $\quad \square$ No $\quad$ If yes, date bilingual services began:

Does the student receive ESL services? $\quad \square$ Yes $\quad \square$ No If yes, date ESL program services began:

If you answered yes to any of the above ELL support services questions, you must attach the complete Language Assessment Scale (LAS LINKS) Grade 8 Student Report.

Required to be completed by the Sending School

Do you recommend this candidate for admission? $\square$ Yes $\square$ No

Comments:

School Name:

Date: 
Signature:

Title: 
APPENDIX E

POLICY REGARDING GRADUATION REQUIREMENTS AND BASIC SKILL REQUIREMENTS FOR GRADUATION 
Policy Regarding Graduation Requirements and Basic Skill Requirements for Graduation

The CTHSS graduate will be expected to attain the following knowledge by content area:

English Language Arts: Demonstrate proficiency, confidence, and fluency in reading, writing, listening, speaking, and viewing; the graduate will explore and respond to classical and contemporary texts from many cultures and historical periods.

Mathematics: Apply a range of numerical, algebraic, geometric, and statistical concepts and skills to formulate, analyze and solve real world problems.

Science: Demonstrate knowledge of the basic concepts of, and interrelationships among biology, chemistry, physics, environmental sciences, and be able to apply scientific skills, processes and methods of inquiry to the real world.

Social Studies: Demonstrate knowledge of history, civics and government, geography and economics, the social sciences, and humanities, including one year of U.S. history and one year in civics/government.

Technology Education: Demonstrate knowledge about the nature, power, influence and effects of technology and be able to design and develop products, systems and environments to solve problems.

Health, Wellness and Physical Fitness: Understand and develop behaviors that promote lifelong health and wellness, and recognize the importance of and participate in physical activities and learning designed to maintain and enhance healthy life styles.

Learning Resources and Information Technology: Use information and technology effectively and be able to apply related strategies to acquire basic skills and content knowledge.

Trade/Technology: Demonstrate the set of skills and competencies required to enter the workforce, be accepted in apprenticeships or pursue postsecondary studies.

\section{Credit Requirements for Graduation}

Beginning with the Class of 2008-2010

Students are expected to schedule and earn sufficient credits each year, in grades $9,10,11$ and 12 in order to meet graduation requirements. Beginning with the Class of 2008 , twenty-eight and one-half credits are required for graduation and must include courses from the following content areas: 
Trade/Technology Program

Cluster Trade Programs

Theory Integrated Within Trade

Exploratory Program (freshmen only)*

Academics

English

Social Studies (includes Civics)

Mathematics

Science
9 credits

3 credits

4 credits

3 credits

3 credits

3 credits

1 credit

$1 / 2$ credit

2 credits

*Includes exploratory for freshmen students only. Two credits will be issued for the first two phases of exploratory and one credit will be issued for phase three. Transfers into the system would come with other courses for application toward graduation.

\section{Promotion Requirements}

- To achieve 10th grade status a student must accumulate 6 credits and receive a 60 or higher in phase III of exploratory and a combined grade of 60 or higher for phase I, II and III of exploratory

- To achieve 11 th grade status a student must accumulate 13.5 credits and receive a 60 or higher in trade/technology

- To achieve 12th grade status a student must accumulate 21 credits and receive a 60 or higher in trade/technology

- Seniors must earn a minimum of 5 credits and must participate in the NOCTI assessment

Promotion requirements are required to enter $10 \mathrm{th}, 11 \mathrm{th}$, and 12 th grade in order to assure that a student has accumulated credits needed for graduation. If students do not meet the minimum credit requirement as they move form grade to grade they will have difficulty graduating in four years.

If a student does not meet the requirements to be promoted to the next grade, he/she may opt to

- repeat their grade if space permits or

- return to their local district.

If a student meets the minimum credit requirement for promotion the student may promote to the next grade with deficiencies, however the student will need to make-up the deficiency prior to graduation either through

- summer make-up, where available, or

- taking the failed course again in subsequent years, when scheduling permits. 
What is meant by a deficiency is that the student could promote with a failure in English knowing that he/she will not graduate with the deficiency and will need to make up the course in subsequent years by taking an additional English course.

\section{Language Arts Labs/Math Labs Required for All Students in Grades Nine and Ten}

The Language Arts and Math labs will give students a grade independent of the English or mathematics grade. Students taking both the Language Arts Lab and Mathematics Lab will receive 1/4 credit each for the school year regardless of the amount of time in each lab. For students taking only the Language Arts Lab or only the Mathematics Lab for the entire year, $1 / 2$ credit will be issued.

The grades earned in the labs will count toward a student's GPA and honor roll. If a student does not attain a 70 or better in the lab, then they are excluded from the honor roll.

Exploratory Program Requirement for Students to Continue Beyond Grade Nine

The Connecticut Technical High School System's exposes each ninth grade student to the technology exploratory program. The exploratory program introduces each student to the goals and objectives for each trade/technology; provides an objective measure of student performance, and a measure of potential for success for each student in all trades/technologies.

The ninth grade exploratory year is viewed as an extension of the admission process that serves as (1) a verification of the student's desire for a technical education and (2) as an assessment of technical aptitudes. The exploratory program is divided into three phases; phase I gives students career information on each trade offered, phase II gives each student a hands-on experience in three trade areas, and phase III a permanent placement where the student begins the study of a technology that he/she will concentrate on for the next three years.

In order for a student to continue in the CTHSS beyond grade nine, he/she must successfully complete the exploratory program. Successful completion is defined as a grade of 60 or higher in phase III as well as a cumulative grade of 60 or higher in the exploratory program. Failure to successfully complete the exploratory program will make it necessary for a student to transfer back to his/her sending district.

\section{Basic Skills Requirement for Graduation}

\section{Language Arts}

\section{Performance Standard}

Students will demonstrate the ability to read a piece of literature and respond critically in writing; read and interpret information; and write using standard English conventions.

\section{Options}

Students have multiple opportunities over the course of their junior and senior year to demonstrate their performance relative to the Language Arts performance standard. Students satisfy the district performance standards for the basic skills in language arts if they have:

1. Achieved a score in either band three (Proficient), four (Goal) or five (Advanced) on a related section of the Connecticut Academic Performance Test - Writing Across the Disciplines and/or Reading Across the Discipline; or 
2. Achieved a score at the 50th percentile or higher on a related section of the Preliminary Scholastic Assessment Test/National Merit Scholarship Qualifying Test or the Scholastic Assessment Test (PSAT/NMSQT/SAT) - verbal and/or writing skills; or

3. Passed the required English 11 or English 12 course with a 70 or higher; or passed an English 11 or English 12 course with a 70 or higher; or completed an independent study project in English with a 70 or higher.

\section{Mathematics}

\section{Performance Standard}

Students shall demonstrate the ability to solve multiple step mathematical problems that require demonstration of basic math operations including fractions, decimals and percentages and the use of algebraic equations; and explain in writing how they arrived at each answer.

\section{Options}

Students have multiple opportunities over the course of their junior and senior year to complete the mathematics performance standard. Students satisfy the district performance standards for basic skills in mathematics if they have:

1. Achieved a score in either band three (Proficient), four (Goal) or five (Advanced) on the Connecticut Academic Performance Test in Mathematics; or

2. Achieved a score at the 50th percentile or higher or the mathematics section of the Preliminary Scholastic Assessment Test/National Merit Scholarship Qualifying Test or the Scholastic Assessment Test (PSAT/NMSQT/SAT), or

3. Passed one of the following courses with a 70 or higher: Algebra II, Pre-Calculus, Calculus, AP Calculus, Statistics, Honors Statistics, AP Statistics or senior math electives; or completed an independent study project in mathematics with a 70 or higher.

\section{Science}

\section{Performance Standard}

Students in the Class of 2008 and beyond shall demonstrate the ability to use scientific inquiry skills to explore world life problems using the content of biology, physics, chemistry and earth science; evaluate the information for validity and reliability; and use that information to support a position on a contemporary scientific issue.

\section{Options}

Students have multiple opportunities over the course of their junior and senior year to complete the performance standard. Students satisfy the district performance standards for basic skills in science if they have:

1. Achieved a score in either band three (Proficient), four (Goal) or five (Advanced) on the 3rd generation of the Connecticut Academic Performance Test in science, or

2. Passed one of the following courses with a 70 or higher, Biology, Chemistry, Physics, Honors Physics, AP Physics, or a senior science electives course; or completed an independent study project in science with a 70 or higher. 


\section{Technology}

\section{Performance Standard}

Students shall demonstrate the set of skills and competencies required to enter the field, be accepted in apprenticeships or pursue post-secondary technical studies as evidenced by their technology portfolio.

\section{Options}

Students have multiple opportunities over the course of their junior and senior year to complete a trade/technology portfolio. The trade/technology portfolio includes a skills checklist and competency assessment list and accomplishments.

\section{Options If Requirements Are Not Met By Date of Graduation}

Seniors who are not eligible for graduation with their class due to their failure to meet the district graduation requirements in one or more subjects as described above, may select one of the following options:

1. Enroll in summer school and pass the requirement and receive a high school diploma; or

2. Return in September as a fifth year student until such requirement is met.

\section{Transfers and Special Cases}

\section{Transfers}

If a student transfers into the Connecticut Technical High Schools (CTHS) after completing at least three years in a high school in another district, they shall be exempt from the CTHS performance standards requirement for graduation.

\section{Special cases}

Performance standards apply to all students requiring special education. The Planning and Placement Team (PPT) may adapt the standard of performance and/or the graduation expectation, by indicating such accommodation in the Individualized Education Plan (IEP).

A student whose primary language is not English may be exempted from the district's performance requirement in one or more standards based on federal and state legislation. The need for the exemption must be directly attributable to the language limitations of the students as indicated on the Bilingual Individual Education Program (BIEP) of the English Language Learners (ELL). A plan of action that includes classroom and language support interventions must be outlined in the student's BIEP.

Guidelines for Participation in Graduation Exercises

1. In order to participate in a Technical High School graduation ceremony, a student must meet the requirements of the Promotion, Retention and Graduation Policy. Students who have not met the graduation requirements may not "walk" during the ceremony.

2. An exception may be made in special circumstances such as:

a. a mistake has been made regarding distribution requirements or promotion requirements;

b. there are emergency health reasons; or

c. absences have been excused, in accordance with the Attendance Policy.

3. A decision relative to special circumstances is the responsibility of the principal; however, an appeal may be brought to the superintendent. 
APPENDIX F

COLLECTIVE EFFICACY BELIEF SCALE 


\section{Collective Teacher Beliefs}

Direcrions: Please isticate your ophaton about eact of the questions below by markto

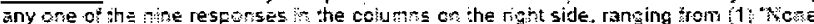

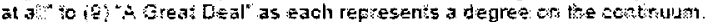

Flease respond to exch of the questions by considering the curreni abirity,

resources, and opportunity of the teaching staff in your school to do each of the folsowing

1. How much can teachers in your school do to produce meaningful student learning?

2. How much can your school do to get students to believe they can do well in schoolwork?

3. To what extent can teacners in your school make expectations clear about appropriate student behavior?

4. To what extent can school personnel in your school establish rules and procedures that facilitate learnging?

5. How much can teachers in your school do to help students master complex content?

5. How much can teachers in your school co to promote deep understanding of academic concepts?

7. How well can teachers in your school respond to defiant situdents?

8. How much can school personnel in your school do to control disruptive behavior?

9. How much can weachers in your schoo do to help students think critically?

10. How well can adults in vour school get students to follow school rules?

7. How much can your school do to foster student creativity?

12. How much can your school do to help students feel safe while they are at school?

For chice use orly.

(e) $\theta \Leftrightarrow \theta \theta \theta$

की०००कीकी

$0 \Leftrightarrow \Leftrightarrow \Leftrightarrow \Leftrightarrow \Leftrightarrow$

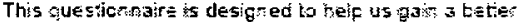
unders:anoing of the tinds ef hings that creste chaltenges for tzachers. Your answers a:e senfisentias.

高

翌

(i)

$\frac{0}{2}$

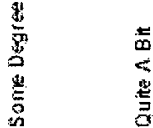

$=$
0
0
0

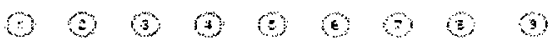

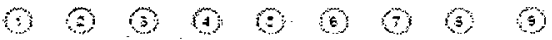

(a) $\Leftrightarrow$ a) $\theta$ की

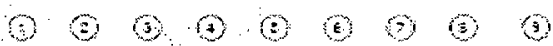

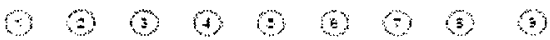

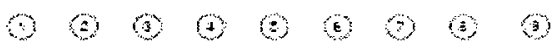

$\Leftrightarrow \Leftrightarrow \Leftrightarrow \theta \Leftrightarrow \theta$

$\Leftrightarrow \Leftrightarrow \Leftrightarrow \Leftrightarrow \Leftrightarrow \theta$

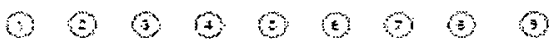

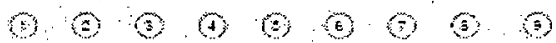

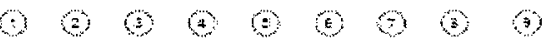


APPENDIX G

CONNECTICUT ACADEMIC PERFORMANCE TEST (CAPT) 
State of Connecticut Department of Education

Purposes and Rationale

The Connecticut General Statutes (Section 10-14n) mandate a statewide assessment to be administered to all public school students in Grade 10. The legislation specifies that the test cannot be used as the sole criterion for graduation or promotion, but that it will be the basis for awarding Certification of Mastery for those students who achieve the state goals in any of the subjects tested. It further specifies that a record of such performance should become part of the student's permanent school record and the official high school transcript. P.A. 01-166 further states that by September 1, 2002, local and regional boards of education must include results from the CAPT when developing criteria to be used in assessing whether students have the basic skills necessary for graduation. This applies to classes graduating in 2006 and after.

The Connecticut Academic Performance Test (CAPT) is a logical extension of the state's long-established testing program. For more than a decade, students have been tested at Grades 4, 6 and 8 on the Connecticut Mastery Test (CMT). The CAPT extends Connecticut's testing program to the high school level, but serves somewhat different purposes than the previously established CMT.

The purposes of the CAPT program are to:

- set high expectations and standards for student achievement on a comprehensive range of important skills and knowledge;

- emphasize the application and integration of skills and knowledge in realistic contexts;

- promote better instruction and curriculum by providing useful test achievement information about students, schools and districts; and

- provide an expanded measure of accountability for all levels of Connecticut's education system up to and including high school.

The CAPT assesses and reports on student performance in four areas: Mathematics, Reading Across the Disciplines (based on a Response to Literature test and a Reading for Information test), Writing Across the Disciplines (based on an Interdisciplinary Writing test and an Editing \& Revising test), and Science. The CAPT requires more from students than other, traditional tests. While traditional assessments typically measure what students know, the CAPT uses state-of-the-art assessment techniques, such as performance tasks, to measure what students can do with what they know. The CAPT measures students' abilities to apply what they have learned in school to situations they may face throughout their lives.

The CMT and CAPT assessments were approved by the United States Department of Education under the Improving America's Schools Act of 1994. 


\section{APPENDIX H}

DESCRIPTION OF PERFORMANCE LEVELS 
Connecticut Academic Performance Test (CAPT)

State of Connecticut Department of Education

Description of Performance Levels

\section{Mathematics}

Advanced: Students who score at this level possess knowledge and skills beyond those necessary to perform the high level of tasks and assignments expected of Connecticut's students. These students demonstrate well-developed conceptual understanding and computational skills as well as an advanced ability to solve complex and abstract mathematical problem

Goal: Students who score at this level possess the knowledge and skills necessary to perform the high level of tasks and assignments expected of Connecticut's students. These students demonstrate well-developed conceptual understanding, computational skills, and problem-solving skills.

Proficient: Students who score at this level demonstrate adequately developed conceptual understanding and computational skills, and adequately developed problem-solving skills.

Basic: Students who score at this level demonstrate adequately developed computational skills, but limited conceptual understanding and problem-solving skills.

Below Basic: Students who score at this level demonstrate some computational skills, but very limited conceptual understanding and problem-solving skills.

Reading

Advanced: Students who score at this level possess knowledge and skills beyond those necessary to perform the high level of tasks and assignments expected of Connecticut's students. Generally, these students can comprehend textbooks and other materials at reading levels beyond their grade, determine the main idea, draw conclusions about the author's purpose and make judgments about the text's quality and themes.

Goal: Students who score at this level possess the knowledge and skills necessary to perform the high level of tasks and assignments expected of Connecticut's students. Generally, these students can comprehend textbooks and other materials intended for their grade level, can determine the main idea, draw conclusions about the author's purpose and make judgments about the text's quality and themes.

Proficient: Students who score at this level can comprehend most grade-level or belowgrade-level textbooks and other materials. They can generally determine the main idea, have an adequate understanding of the author's purpose and are able to make some judgments about a text's quality and themes.

Basic: Students who score at this level have difficulty comprehending below grade-level textbooks and other materials. They may also have difficult determining the main idea, 
understanding the author's purpose and making judgments about a text's quality and themes.

Below Basic: Students who score at this level have difficulty comprehending below grade-level textbooks and other materials. They also have difficult determining the main idea, understanding the author's purpose and making judgments about a text's quality and themes.

Writing

Advanced: Students who score at this level possess knowledge and skills beyond those necessary to perform the high level of tasks and assignments expected of Connecticut's students. Generally, these students can produce papers that show strong organization, and are fluent, well-developed, and fully elaborated with specific details. These students also possess the skills necessary to compose, edit and revise a written piece.

Goal: Students who score at this level possess the knowledge and skills necessary to perform the high level of tasks and assignments expected of Connecticut's students. Generally, these students can produce fluent papers that are well-developed, well organized, and elaborated with general and specific details. These students also generally possess the skills necessary to compose, edit and revise a written piece.

Proficient: Students who score at this level generally can produce papers that are fluent, organized, developed and elaborated with some details. They also possess most of the skills necessary to compose, edit and revise a written piece.

Basic: Students who score at this level generally produce papers that are underdeveloped, brief with few details and sometimes confusing due to lack of organization or fluency. These students tend to demonstrate limited skills to compose edit and revise a written piece.

Below Basic: Students who score at this level generally produce papers, which are very weak responses. These papers may be too brief to indicate organization, or they may be awkward and confusing. These students tend to demonstrate very limited skills to compose, edit and revise a written piece. 
APPENDIX I

CONNECTICUT ACADEMIC PERFORMANCE TEST (CAPT) ADMINISTRATION 
STATE OF CONNECTICUT

STATE DEPARTMENT OF EDUCATION

Connecticut Academic Performance Test (CAPT) Administration

Testing contractors:

Harcourt Educational Measurement (HEM): contractor for census (live) testing Questar, Inc., located in Apple Valley, MN: CAPT supplemental testing.

\section{Testing Sessions}

The length of time for each CAPT session is specified below, broken down into actual student testing time and additional administration time necessary for distributing materials and reading directions.

Test Session Testing Directions Total Time

Response to Literature: 70 minutes 10 minutes 80 minutes

Reading for Information: 45 minutes 15 minutes 60 minutes

Mathematics:

Session I 75 minutes 15 minutes 90 minutes

Break: If both sessions are given on the same day 10-30 minutes

Session II 75 minutes 5 minutes** 80 minutes

Science:

Session I 50 minutes 15 minutes 65 minutes

Break: If both sessions are given on the same day 10-30 minutes

Session II 50 minutes 5 minutes** 55 minutes

Interdisciplinary Writing:

Session I 65 minutes 15 minutes 80 minutes

Session II 65 minutes 15 minutes 80 minutes

Editing \& Revising 25 minutes 10 minutes 35 minutes

** Allow 15 minutes for directions if administered on separate days.

$\square$ Within a school, each section of the test must be administered to all Grade 10 students and retest students in grades 11 and 12 at the same time on the same day.

$\square$ According to state law, CAPT testing may not begin prior to 9:00 a.m.

$\square$ Due to the participation rate requirements of No Child Left Behind, it is essential to test all grade 10 students during the test administration window of March 1-28, 2006 inclusive.

Students who are absent from any subtest should be administered a make-up test as soon as they return to school in order to ensure that they participate in all CAPT subtests. $\square$ Students must be tested in a regular classroom setting. The test may not be administered to a large group of students that exceeds a normal class size. If a room other than a regular classroom is used (e.g., library, cafeteria), only one normal class size 
of students may be tested in that setting. Please note that there is no minimum number of students required within a setting.

$\square$ There are test setting accommodations available to students enrolled in special education and for students who are English Language Learners. For a complete list of available accommodations, refer to the Assessment Guidelines available on the CSDE website (www.state.ct.us/sde).

$\square$ Mathematics sessions II and I do not need to be administered on the same day. Separate test booklets will be produced for each session. If you choose to administer the Mathematics sessions on separate days, allow an additional 15 minutes for directions on day two.

$\square$ Science sessions II and I do not need to be administered on the same day. Separate test booklets will be produced for each session. If you choose to administer the Science sessions on separate days, allow an additional 15 minutes for directions on day two.

$\square$ Be advised that students must participate in each subtest or testing session for a given content area in order to earn a score. For example, if a student completes one Mathematics session and is absent for the second session, the student will be reported as ABSENT for Mathematics. If a student completes one Mathematics session and leaves the second session blank, the student will be reported as LEFT BLANK for Mathematics. The same reporting rules apply to Science, Reading Across the Disciplines, and Writing Across the Disciplines.

$\square$ A maximum of two sessions of testing may be scheduled per day. For instance, the Response to Literature and the Editing \& Revising tests may be administered on the same day. This applies to make-up testing as well.

$\square$ When administering two sessions on the same day, a break of between 10 and 30 minutes should be allowed between sessions.

$\square$ Each student must have a calculator for the entire Mathematics test. Students may use any calculator provided to them or any calculator of their choosing, including those with limited text entry capabilities such as some scientific and graphing calculators. The use of a Personal Digital Assistant such as a Palm Pilot is not permitted.

$\square$ There is a Science hands-on activity that must be administered prior to the test. Reminder: there are Braille and large-print versions of the Science Performance Task which should be used with students receiving these accommodations. 
REFERENCE LIST 


\section{REFERENCE LIST}

Adams, C. M. (2003). The effects of school structure and trust on collective efficacy. Unpublished doctoral dissertation, Oklahoma State University, Tulsa.

Ali, S. R., McWhirter, E. H., \& Chronister, K. M. (2005). Self-efficacy and vocational outcome expectations for adolescents of lower socioeconomic status: A pilot study. Journal of Career Assessment, 13(1), 40-58.

Ali, S. R., \& Saunders, J. L. (2006). College expectations of rural Appalacian youth: An exploration of Social Cognitive Career Theory factors. Career Development Quarterly, 55, 38-51.

Allen, C. K. (2003). Making sense of context: An analysis of mesosystemic influences impacting first-and second-year beginning teachers' sense of efficacy. Unpublished doctoral dissertation, Baylor University, Waco, TX.

Allinder, R. M. (1995). An examination of the relationship between teacher efficacy and curriculum-based measurement and student achievement. Remedial \& Special Education, 16(4), 24.

Armstrong-Coppins, D. R. (2003). What principals do to increase collective teacher efficacy in urban schools. Unpublished doctoral dissertation, Cardinal Stritch University, Milwaukee, WI.

Bandura, A. (1986). Social foundations of thought and action. Englewood Cliffs, NJ: Prentice Hall.

Bandura, A. (1989a). Human agency in social cognitive theory. American Psychologist, 44(9), 115-1184.

Bandura, A. (1989b). Regulations of cognitive processes through perceived self-efficacy. Developmental Psychology, 25(5), 729-735.

Bandura, A. (1997). Self-efficacy: The exercise of control. New York: W. H. Freeman.

Bandura, A. (2000). Exercise of human agency through collective efficacy. American Psychological Society, 9(3), 75-79. 
Bandura, A. (2001). Social cognitive theory: An agentic perspective. Annual Reviews in Psychology, 52, 1-26.

Bandura, A. (2003). On the psychosocial impact of spiritual modeling. The International Journal for the Psychology of Religion, 13(3), 167-173.

Bandura, A. (2004). Health promotion by social cognitive means. Health Education \& Behavior, 31(2), 143-164.

Bandura, A. (2005). The primacy of self-regulation in health promotion. Applied Psychology: An International Review, 54(2), 245-254.

Bandura, A., Caprara, G. V., Barbaranelli, C., Gerbino, M., \& Pastorelli, C. (2003). Role of affective self-regulatory efficacy in diverse spheres of psychosocial functioning. Child Development, 74(3), 769-782.

Benight, C. C., \& Bandura, A. (2004). Social cognitive theory of posttraumatic recovery: The role of perceived self-efficacy. Behavior Research and Therapy, 42, 11291148 .

Betz, N. E., \& Hackett, G. (1981). The relationship of career-related self-efficacy expectations to perceived career options in college women and men. Journal of Counseling Psychology, 28, 399-410.

Betz, N. E., \& Hackett, G. (1983). The relationship of mathematics self-efficacy expectations to the selection of science-based college majors. Journal of Vocational Behavior, 23, 329-345.

Betz, N. E., \& Hackett, G. (1986). Applications of self efficacy theory to understanding career choice behavior. Journal of Social and Clinical Psychology, 4, 279-289.

Brekke, M., Hjortdahl, P., \& Kvien, T. K. (2001). Self-efficacy and health status in rheumatoid arthritis: A two-year longitudinal observational study. Rheumatology, 40, 387-392.

Brophy, J. E. (1986). Teacher influences on student achievement. American Psychologist, 4l(10), 1069-1077.

Burton, L. D. (1995). Teacher efficacy and the use of specific instructional practices by seventh-and eighth-grade science teachers in the United States. Unpublished doctoral dissertation, Andrews University, Berrien Springs, MI.

Cannon, S. M. (2004). Supporting first-year college women in science and related majors: A career development intervention. Unpublished doctoral dissertation, North Carolina State University, Raleigh. 
Cargill, B. R., Clark, M., Pera, V., S., Niaura, R. S., \& Abrams, D. P. (1999). Binge eating, body image, depression, and self-efficacy in an obese clinical population. Obesity Research, 7, 379-386.

Charvez, R. J. (2004). The effects of interdependence structure and trust on outcomes in work groups. Unpublished doctoral dissertation, University of Colorado, Boulder.

Chemers, M. M., Hu, L., \& Garcia, B. F. (2001). Academic self-efficacy and first-year college student performance and adjustment. Journal of Educational Psychology, 93(1), 55-64.

Coelho, R. J. (1984). Self-efficacy and cessation of smoking. Psychological Reports, 54, 309-310.

Coladarci, T. (1992). Teachers' sense of efficacy and commitment to teaching. Journal of Experimental Education, 60, 323-337.

Coladarci, T., \& Fink, D. R. (1995). Correlations among measures of teacher efficacy: Are they measuring the same thing? Paper presented at the Annual Meeting of the American Educational Resource Association, San Francisco, CA.

Collins, P. D. (2001). Personal teaching efficacy and collective efficacy: A case study of teachers' beliefs during mandated change. Unpublished doctoral dissertation, The University of Akron, $\mathrm{OH}$.

Cybulski, T. G. (2003). Investigating the role of the collective efficacy of teachers in fiscal efficiency and student achievement. Unpublished doctoral dissertation, The Ohio State University, Columbus.

Cybulski, T. G., Hoy, W. K., \& Sweetland, S. R. (2005). The roles of collective efficacy of teachers and fiscal efficiency in student achievement. Journal of Educational Administration, 43(5), 439-461.

Dale, R. L. (2004). The effects of teacher collaboration and school trust on collective efficacy. Unpublished doctoral dissertation, Oklahoma State University, Tulsa.

Dellinger, A. M. B. (2001). A study of the measurement and sources of teachers' self and collective efficacy beliefs in professional learning environments. Unpublished doctoral dissertation, Louisiana State University and Agricultural \& Mechanical College, Baton Rouge.

Dougher, M. J. (1995). A bigger picture: Cause and cognition in relation to differing scientific frameworks. Journal of Behavior Therapy and Experimental Psychiatry, $26(3), 215-219$. 
Earley, P. C., \& Randel, A. (1995). Cognitive causal mechanisms in human agency: Etic and emic considerations. Journal of Behavior Therapy and Experimental Psychiatry, 26(3), 221-227.

Elmore, R. F. (1990). Restructuring schools: The next generation of educational reform. San Francisco, CA: Jossey-Bass.

Elmore, R. F. (2006). School reform from the inside out. Cambridge, MA: Harvard Education Press.

Elmore, R. F., Peterson, P. L., \& McCarthey, S. J. (1996). Restructuring in the classroom: Teaching, learning, and school organization. San Francisco, CA: Jossey-Bass.

Emmer, E., \& Hickman, J. (1991). Teacher efficacy in classroom management and discipline. Educational and Psychological Measurement, 51, 755-765.

Freud, S. (1989). Civilization and its discontents (J. Strachey, Trans.). New York: W. W. Norton \& Company. (Original work published 1930)

Garcia, H. (2004). The impact of collective efficacy on student achievement: Implications for building a learning community. Unpublished doctoral dissertation, Loyola University, Chicago.

Gibson, S., \& Dembo, M. H. (1984). Teacher efficacy: A construct validation. Journal of Educational Psychology, 76, 569-582.

Gist, M. E., \& Mitchell, T. R. (1992). Self-efficacy: A theoretical analysis of its determinants and malleability. Academy of Management Review, 17(2), 183-211.

Glenn, S. D. (2003). Filling the leadership void: The impact of peer and coach leaders on team dynamics. Unpublished doctoral dissertation, University of Idaho, Moscow.

Goals 2000: Educate America Act, 20 U.S.C. $\$ 5811$ et seq. (1994).

Goddard, R. D. (2002). A theoretical and empirical analysis of the measurement of collective efficacy: The development of a short form. Educational and Psychological Measurement, 62(1), 97-110.

Goddard, R. D., \& Goddard, Y. (2001). A multilevel analysis of the relationship between teacher and collective efficacy in urban schools. Teaching and Teacher Education, 17, 807-818.

Goddard, R. D., Hoy, W. K., \& Woolfolk Hoy, A. (2004). Collective efficacy beliefs: Theoretical developments, empirical evidence, and future directions. Educational Researcher, 33(3), 3-13. 
Goddard, R. D., LoGerfo, L., \& Hoy, W. K. (2004). High school accountability: The role of collective efficacy. Educational Policy, 18(30), 403-425.

Goddard, R. D., Sweetland, S. R., \& Hoy, W. K. (2000). Academic emphasis of urban elementary schools and student achievement in reading and mathematics: A multilevel analysis. Educational Administration Quarterly, 36, 5.

Grass, K. (2004). Collective efficacy and increasing student achievement: A case study of one improving high poverty school. Unpublished doctoral dissertation, University of Virginia, Charlottesville.

Gushue, G. V., Scanlan, K. R. L., Pantzer, K. M., \& Clarke, C. P. (2006). The relationship of career decision-making self-efficacy, vocational identity, and career exploration behavior in African American high school students. Journal of Career Development, 33(1), 19-28.

Gushue, G. V., \& Whitson, M. L. (2006). The relationship among support, ethnic identity, career decision self-efficacy, and outcome expectations in African American high school students. Journal of Career Development, 33(2), 112-124.

Guskey, T. R. (2000). Evaluating professional development. Thousand Oaks, CA: Corwin Press.

Guskey, T. R., \& Passaro, P. (1994). Teacher efficacy: A study of construct dimensions. American Educational Research Journal, 31, 627-643.

Gwilliam, L., \& Betz, N. (2001). Validity of measures of math- and science-related selfefficacy for African Americans and European Americans. Journal of Career Assessment, 9(3), 261-282.

Haaga, D. A., \& Stewart, B. L. (1992). Self-efficacy for recovery from a lapse after smoking cessation. Journal of Consulting and Clinical Psychology, 60, 24-28.

Hackett, G., \& Betz, N. E. (1981). A self-efficacy approach to the career development of women. Journal of Vocational Behavior, 18(3), 326-329.

Hackett, G., \& Betz, N. E. (1989). An exploration of the mathematics self-efficacy/ mathematics performance correspondence. Journal for Research in Mathematics Education, 20(3), 261-273.

Hall, G. E., \& Hord, S. M. (2006). Implementing change: Patterns, principles and potholes. Boston, MA: Pearson Education.

Hawkins, R. M. F. (1995). Self-efficacy: A cause of debate. Journal of Behavior Therapy and Experimental Psychiatry, 26(3), 235-240. 
Hoy, W. K., Smith, P.A., \& Sweetland, S. R. (2002). A test of a model of school achievement in rural schools: The significance of collective efficacy. In W. K. Hoy \& C. Miskel (Eds.), Theory and research in educational administration (Vol. 1, pp. 185-202). Greenwich, CT: Information Age Publishing.

Hoy, W. K., Sweetland, S. R., \& Smith, P. A. (2002). Toward an organizational model of achievement in high schools: The significance of collective efficacy. Educational Administration Quarterly, 38, 77-93.

Ji, P. Y., Lapan, R. T., \& Tate, K. (2004). Vocational interests and career efficacy expectations in relation to occupational sex-typing beliefs for eighth grade students. Journal of Career Development, 31(2), 143-154.

Johnson, B., \& Stevens, J. J. (2006). Student achievement and elementary teachers' perceptions of school climate. Learning Environments Research, 9(2), 111-122.

Johnson, S. M., \& Donaldson, M. L. (2007). Overcoming the obstacles of leadership. Educational Leadership, 65(1), 8-13.

Knobloch, N., A. (2002). Exploration of effects caused by the first ten weeks of the school year on teacher efficacy of student teachers and novice teachers in agricultural education in Ohio. Unpublished doctoral dissertation, The Ohio State University, Columbus.

Knobloch, N., A., \& Whittington, M. S. (2003). Novice teachers' perceptions of support, teacher preparation quality, and student teaching experience related to teacher efficacy. Journal of Vocational Education Research, 27(3), 331-341.

Lapan, R. T., Shaughnessy, P., \& Boggs, K. (1996). Efficacy expectations and vocational interests as mediators between sex and choice of math/science college majors: A longitudinal study. Journal of Vocational Behavior, 49(3), 277-291.

Larrick, C. S. (2004). Collective efficacy and student achievement. Unpublished doctoral dissertation, University of Virginia, Charlottesville.

Lee, V. E., \& Smith, J. B. (1996). Collective responsibility for learning and its effects on gains in achievement for early secondary school students. American Journal of Education, 104(2), 103-147.

Lent, R. W., Brown, S. D., \& Hackett, G. (1994). Toward a unifying social cognitive theory of career and academic interest, choice, and performance. Journal of Vocational Behavior, 45, 79-122. 
LeRoy, K. A. (2005). Baldrige education criteria for performance excellence: Perceptions of district personnel of implementation and impact on collective teacher efficacy. Unpublished doctoral dissertation, Texas A\&M University, College Station.

Lin, S. J. (2001). The relationship between collective efficacy and task interdependence. Unpublished doctoral dissertation, University of Southern California, Los Angeles.

Lindley, L. D. (2006). The paradox of self-efficacy: Research with diverse populations. Journal of Career Assessment, 14(1), 143-160.

Loucks, S. F., Newlove, B. W., \& Hall, G. E. (1998). Measuring levels of use of the innovation: A manual for trainers, interviewers, and raters. Austin, TX: Southwest Educational Development Laboratory.

Luzzo, D. A., \& McWhirter, E. H. (2001). Sex and ethnic differences in the perception of educational and career-related barriers and levels of coping efficacy. Journal of Counseling \& Development 79(1), 61-67.

Mackenzie, S. V. (2000). Collective efficacy and collaborative climate in Maine high schools. Unpublished doctoral dissertation, University of Maine, Orono.

Malloch, M. (1999). Future paths and challenges for quality and diversity in vocational education and training. Paper presented at the Australian Vocational Education and Training Research Association, Melbourne, Victoria, Australia.

Malpass, J., O'Neil, H., \& Hocevar, D. (1996). Self-regulation, goal orientation, selfefficacy and math achievement. Paper presented at the annual meeting of the American Educational Research Association, New York.

Marin, B. J. (2001). A case analysis of the perceptions of efficacious teachers in school cultures that support educational change. Unpublished doctoral dissertation, Duquesne University, Pittsburgh.

Marks, M. A. (1999). A test of the impact of collective efficacy in routine and novel performance environments. Hüman Performance, 12(3/4), 295-320.

Mau, W. C. (2003). Factors that influence persistence in science and engineering career aspirations. Career Development Quarterly, 51(3), 234-243.

Mawhinney, H. B., Haas, J., \& Wood, C. (2005). Teachers' perceptions of collective efficacy and school conditions for professional learning. Paper presented at the annual meeting of the University Council for Educational Administration, Nashville, TN. 
Meier, S., McCarthy, P., \& Schmeck, R. (1984). Validity of self-efficacy as a predictor of writing performance. Cognitive Therapy and Research, 8(2), 107-120.

Midgley, C., Feldlaufer, H., \& Eccles, J. S. (1989). Change in teacher efficacy and student self- and task-related mathematics during the transition to junior high school. Journal of Educational Psychology, 81(2), 247-258.

No Child Left Behind Act, 20 U.S.C. $§ 6301$ et seq. (2001).

Ochs, L. A., Roessler, R. T. (2004). Predictors of career exploration intentions: A social cognitive career theory perspective. Rehabilitation Counseling Bulletin (ARCA), $47(4), 224-233$.

Olivier, D. F. (2001). Teacher personal and school culture characteristics in effective schools: Toward a model of a professional learning community. Unpublished doctoral dissertation, Louisiana State University and Agricultural \& Mechanical College, Baton Rouge.

Oxendine, O. H. (2005). The sources that contribute to the self-efficacy beliefs of teachers during the early stages of implementing comprehensive changes in reading instruction. Unpublished doctoral dissertation, The University of North Carolina at Greensboro.

Pajares, F. (1996). Self-efficacy beliefs in academic settings. Review of Educational Research, 66(4), 543-578.

Pajares, F. (1997). Current directions in self-efficacy research. In M. Maehr \& P. R. Pintrich (Eds.), Advances in motivation and achievement (Vol. 10, pp. 1-49). Greenwich, CT: JAI Press.

Pajares, F. (2003). Self-efficacy beliefs, motivation and achievement in writing: A review of the literature. Reading \& Writing Quarterly, 19, 139-158.

Pajares, F., Miller, M. D., \& Johnson, M. J. (1999). Gender differences in writing selfbeliefs of elementary school students. Journal of Educational Psychology, 91, 5061.

Pavlov, I. (1927). Lecture 1: Conditioned reflexes: An investigation of the physiological activity of the cerebral cortex (G. V. Anrep, Trans.). Retrieved January 31, 2008, from http://www.ivanpavlov.com/lectures/ivan_pavlov-lecture_001.htm

Pedhazur, E. (1982). Multiple regression in behavioral research: Explanation and prediction. New York: Holt, Rinehart \& Winston. 
Pederson, L., Strickland, C., \& DesLauriers, A. (1991). Self-efficacy related to smoking cessation in general practice patients. International Journal of the Addictions, 26, 467-485.

Pintrich, P. R., \& De Groot, E. V. (1990). Motivational and self-regulated learning components of classroom academic performance. Journal of Educational Psychology, 82(1), 33-40.

Pintrich, P. R., \& Schunk, D. (1996). Motivation in education: Theory, research \& applications. Englewood Cliffs, CA: Prentice-Hall.

Reese, E. J., Reese, M., \& Tausner, M. R. (1995). Systems models provide a view of psychological self-organization. Retrieved January 31, 2008, from http://www.nlpinfo.com

Reeves, D. B. (2004). Accountability for learning: How teachers and school leaders can take charge. Alexandria, VA: Association for Supervision and Curriculum Development.

Riggs, I., \& Enochs, L. (1990). Toward the development of an elementary teacher's science teaching efficacy belief instrument. Science Education, 74, 625-638.

Riggs, M. L., Warka, J., Babasa, B., Betancourt, R., \& Hooker, S. (1994). Development and validation of self-efficacy and outcome expectancy scales for job related applications. Educational and Psychological Measurement, 54, 793-802.

Ross, J. A. (1994). Beliefs that make a difference: The origins and impacts of teacher efficacy. Paper presented at the Canadian Association for Curriculum Studies, Calgary, Alberta, Canada.

Ross, J. A., \& Gray, P. (2004). Transformational leadership and teacher commitment to organizational values: The mediating effects of collective teacher efficacy. Paper presented at the Canadian Association for Curriculum Studies, Calgary, Alberta, Canada.

Ross, J. A., Hogaboam-Gray, A., \& Gray, P. (2004). Prior student achievement, collaborative school processes, and collective teacher efficacy. Leadership and Policy in Schools, 3(3), 163-188.

Rotter, J. (1966). Generalized expectancies for internal versus external control of reinforcement. Psychological Monographs: General and Applied, 80(1), 1-28.

Schunk, D. H. (1983). Developing children's self-efficacy and skills: The roles of social comparative information and goal setting. Contemporary Educational Psychology, 8, 76-86. 
Scott, C. (2003). Organizational effectiveness: Its relationship to teacher efficacy and school climate. Unpublished doctoral dissertation, St. John's University, New York.

Shields, C. A., \& Brawley, L. R. (2006). Preferring proxy-agency: Impact on selfefficacy for exercise. Journal of Health Psychology, 11(6), 904-914.

Skinner, B. F. (1938). The behavior of organisms: An experimental analysis. Cambridge, MA: B. F. Skinner Foundation.

Skinner, B. F. (1958). Teaching machines. Science Education, 128 (3330), 969-977.

Smith, P. A., Hoy, W. K., \& Sweetland, S. R. (2002, April). Collective efficacy and achievement in rural schools. Paper presented at the annual meeting of the American Educational Research Association, New Orleans, LA.

Stricker, G., \& Gold, J. R. (2004). Psychotherapy integration: An assimilative, psychodynamic approach. Clinical Psychology: Science and Practice, 3, 47-58.

Tagger, L. S. (2002). The relationship of collective efficacy and performance in supervision. Unpublished doctoral dissertation, Indiana University, Bloomington.

Tasa, K. G. (2002). The impact of collective efficacy on issue interpretation and strategic decision-making processes and outcomes. Unpublished doctoral dissertation, The University of Toronto, Ontario, Canada.

Tracz, S. M., \& Gibson, S. (1986). Effects of efficacy on academic achievement. Paper presented at the Annual Meeting of the California Educational Research Association, Marina Del Ray, CA.

Tschannen-Moran, M., \& Barr, M. (2004). Fostering student learning: The relationship of collective teacher efficacy and student achievement. Leadership and Policy in Schools, 3, 187-207.

Tschannen-Moran, M., \& Woolfolk Hoy, A. (2001). Teacher efficacy: Capturing an elusive construct. Teaching and Teacher Education, 17, 783-805.

Tschannen-Moran, M., Woolfolk Hoy, A., \& Hoy, W. K. (1998). Teacher efficacy: Its meaning and measure. Review of Educational Research, 68(2), 202-248.

U.S. Department of Education. (1983). A nation at risk: The imperative for educational reform. Retrieved January 29, 2008, from http:/www.ed.gov/pubs/ NatAtRisk/ risk.html 
U.S. Department of Education. (2005). Flexibility for states raising achievement for students with disabilities. Retrieved January 31, 2008, from http://www.ed.gov/ policy/elsec/guid/raising/disab-factsheet.doc

U.S. Department of Education. (2006). Highly qualified teachers for every child. Retrieved January 31, 2008, from http:/www.ed.gov/nclb/methods/ teachers/stateplanfacts.html

Vaz, A. W. (2006). An analysis of student performance in Connecticut technical high schools as measured by 2001 CAPT and 2003 NOCTI assessment. Unpublished doctoral dissertation, Central Connecticut State University, New Britain.

Walumbwa, F. O., Wang, P., Lawler, J. J., \& Shi, K. (2004). The role of collective efficacy in the relations between transformational leadership and work outcomes. Journal of Occupational and Organizational Psychology, 77, 515-530.

Watson, J. (2006). Psychology as the behaviorist views it. Journal of Health Psychology, 11(6), 904-914.

Weber, B. J., \& Omotani, L. M. (1994). The power of believing. Executive Educator, 16(9), 35-38.

Weiss, S. (2005). Principals and superintendents play significant - and frequently underestimated-role in teaching and learning process. District and School Leadership, 6(2), 1.

WestEd. (2003). Closing the achievement gap: Lessons from California. $R \& D$ Alert, $5(1), 1-4$.

Zimmerman, B. J. (2000). Self-efficacy: An essential motive to learn. Contemporary Educational Psychology, 25, 82-91.

Zimmerman, B., \& Bandura, A. (1994). Impact of self-regulatory influences on writing course attainment. American Educational Research Journal, 31(4), 845-862.

Zimmerman, B. J., Bandura, A., \& Martinez-Pons, M. (1992). Self-motivation for academic attainment: The role of self-efficacy beliefs and personal goal setting. American Educational Research Journal, 29, 663-67. 



\author{
Rosemary Tralli \\ 431 Ash Swamp Road \\ Glastonbury, CT 06033 \\ (860) 659-8183
}

\title{
$\underline{\text { Education }}$
}

2008 Doctoral Candidate, Leadership, Andrews University

1997 Certificate of Advance Graduate Study, Administration, University of Connecticut

1984 Master of Science, Counseling, Central Connecticut State University

1975 Bachelor of Science, Special Education, Southern Connecticut State University

\section{Professional Experience}

1999 - present:Education Consultant providing professional development training in curriculum and instruction, systems change consultation and administrative support to districts and organizations at local, state and national levels; external affiliation with the Center for Research on Learning, University of Kansas.

1999 - 2006: Education Consultant, Capitol Region Education Council, Hartford, CT Duties involved creating, implementing and assessing paraprofessional programs and workshops on inclusive practices.

1998 - 1999: Special Education Coordinator, Enfield Public Schools, Enfield, CT. Administrative duties included preschool through high school case supervision, program development and management, staff supervision and evaluation.

1986 - 1998: Learning Disabilities Teacher/Consultant, Wethersfield High School, Wethersfield, CT. Taught students with learning disabilities and attentional disorders through resource services and general education collaboration; administered educational evaluations; provided districtwide teacher in-services in strategies and content enhancement routines.

1986 - 1988: Learning Disabilities Consultant, Silas Deane Middle School, Wethersfield, CT. Provided consultative services to all teacher teams; administered educational evaluations; developed the Strategies Intervention Model Demonstration Site to provide state and national visitors with opportunities to experience strategic learning processes within a middle school setting (site opened for 1992 and 1993 school years).

1977 - 1986: Special Education Teacher, East Windsor High School, East Windsor, CT. Provided academic and social skill instruction in a self-contained program for students with learning, attentional, and behavioral needs. 